\title{
Statins: a repurposed drug to fight cancer
}

Wen Jiang ${ }^{1+}$, Jin-Wei Hu ${ }^{1+}$, Xu-Ran He${ }^{2}$, Wei-Lin Jin $^{3^{*}}$ (I) and Xin-Yang He $\mathrm{4}^{4^{*}}$

\begin{abstract}
As competitive HMG-CoA reductase (HMGCR) inhibitors, statins not only reduce cholesterol and improve cardiovascular risk, but also exhibit pleiotropic effects that are independent of their lipid-lowering effects. Among them, the anti-cancer properties of statins have attracted much attention and indicated the potential of statins as repurposed drugs for the treatment of cancer. A large number of clinical and epidemiological studies have described the anticancer properties of statins, but the evidence for anticancer effectiveness of statins is inconsistent. It may be that certain molecular subtypes of cancer are more vulnerable to statin therapy than others. Whether statins have clinical anticancer effects is still an active area of research. Statins appear to enhance the efficacy and address the shortcomings associated with conventional cancer treatments, suggesting that statins should be considered in the context of combined therapies for cancer. Here, we present a comprehensive review of the potential of statins in anti-cancer treatments. We discuss the current understanding of the mechanisms underlying the anti-cancer properties of statins and their effects on different malignancies. We also provide recommendations for the design of future well-designed clinical trials of the anti-cancer efficacy of statins.
\end{abstract}

Keywords: Drug repurposing, Mevalonate pathway, Statins, Synergistic antitumor, Tumor microenvironment

\section{Background}

Currently, cancer remains the leading cause of death in every country in the world, and the burden of cancer morbidity and mortality is growing rapidly worldwide [1]. The global cancer burden in 2040 is expected to be 28.4 million cases, representing an increase of $47 \%$ over 2020 [1]. The development of new drugs to improve cancer treatment can take many years and is extremely expensive [2]. One way to reduce this time-frame and cost is to repurpose existing drugs that show potential cytotoxic activity. Drug repurposing has been used in cancer treatment for many years. Although these drugs have an

\footnotetext{
*Correspondence: Idyy_jinwl@|zu.edu.cn; weilinjin@yahoo.com; hxy2333@126.com

${ }^{+}$Wen Jiang and Jin-Wei Hu contributed equally to this work.

${ }^{3}$ Institute of Cancer Neuroscience, Medical Frontier Innovation Research Center, The First Hospital of Lanzhou University, The First Clinical Medical College of Lanzhou University, Lanzhou 730000, P. R. China

${ }^{4}$ Department of General Surgery, The First Affiliated Hospital of University of Science and Technology of China (Anhui Provincial Hospital), Hefei 230001, P. R. China

Full list of author information is available at the end of the article
}

alternative original indication, they are now being widely used in cancer treatment [3].

Statins are powerful competitive inhibitors of 3-hydroxy-3-methyl-glutaryl-CoA (HMG-CoA) reductase (HMGCR) and are commonly used as lipid-lowering drugs. The source of human plasma cholesterol is either dietary intake or de novo biosynthesis by cells. Statins reduce plasma cholesterol levels by reducing de novo cholesterol biosynthesis and inducing changes in lowdensity lipoprotein (LDL) receptor expression. However, in the past, studies have shown that statins exhibit pleiotropic effects independent of their lipid-lowering properties. It has been reported that the epigenetic effects of statins mediate these pleiotropic effects, at least to some extent [4]. Among them, the anti-tumor properties of statins have attracted particular attention. For example, Kodach et al. found that statins act as DNA methyltransferase (DNMT) inhibitors, demethylating the bone morphogenetic protein 2 (BMP2) promoter, activating BMP signaling, inducing differentiation of colorectal cancer (CRC) cells, and reducing "stemness" [5]. As repurposed drugs, statins are being investigated original author(s) and the source, provide a link to the Creative Commons licence, and indicate if changes were made. The images or other third party material in this article are included in the article's Creative Commons licence, unless indicated otherwise in a credit line to the material. If material is not included in the article's Creative Commons licence and your intended use is not permitted by statutory regulation or exceeds the permitted use, you will need to obtain permission directly from the copyright holder. To view a copy of this licence, visit http://creativecommons.org/licenses/by/4.0/. The Creative Commons Public Domain Dedication waiver (http://creativeco mmons.org/publicdomain/zero/1.0/) applies to the data made available in this article, unless otherwise stated in a credit line to the data. 
for both the prevention and treatment of cancer. Therefore, the anticancer mechanisms of statins have attracted a lot of attention. Among them, the most widely studied is the mevalonate pathway. The flux of the mevalonate pathway is an absolute requirement for all cells, including cancer cells. YAP and TAZ are master transcriptional regulators of normal organ growth and tumor growth [6]. Studies have revealed that the mevalonate pathway promotes YAP/TAZ nuclear localization and activity, while statins impair the YAP/TAZ-dependent transcriptional responses by blocking the mevalonate pathway, thereby inhibiting the development of cancer cells [7]. In addition to the mevalonate pathway, a variety of other anticancer mechanisms of statins have been uncovered one after another.

The development of statins as "cholesterol-lowering" drugs began in the mid-1970s. Simvastatin, lovastatin, and pravastatin are all fungal-derived compounds with very similar structures, although the additional hydroxyl groups make pravastatin more hydrophilic than simvastatin or lovastatin. In contrast, fluvastatin, pitavastatin, cerivastatin, atorvastatin and rosuvastatin are synthetic derivative compounds with similarities in structure, such as common fluoride side groups (Fig. 1). Statins may have different intracellular effects depending on their chemical structure [8]. Compared with hydrophilic statins (such as pravastatin and rosuvastatin), lipophilic statins (such as simvastatin) show a greater ability to penetrate the cell membrane and enter hepatocytes and non-hepatocytes through passive diffusion $[9,10]$. Furthermore, lipophilic statins have higher pro-apoptotic activity than hydrophilic statins [11]. Due to their higher cytotoxic potential, lipophilic statins may be beneficial in cancer treatment [12].

Here, we review the anti-cancer mechanisms of statins as well as the new perspectives and unique significance of statins in adjuvant cancer therapy to provide a reference for future clinical trials and applications of statins.

\section{Conventional and off-label of statins}

Statins were initially developed to lower lipids and prevent cardiovascular disease. Statins act as competitive inhibitors of HMGCR and can prevent cardiovascular diseases such as atherosclerosis by reducing cholesterol synthesis [13-15]. The effect of statins on cardiovascular morbidity and mortality in patients with and without atherosclerotic disease has been well proven. Furthermore, statins appear to exert pleiotropic effects independent of their lipid-lowering properties, including effects on diabetes, neurological diseases, coronary heart disease, inflammation and cancer [16]. Given the anticancer effects of statins, and the fact that statins are

\section{Lovastatin}<smiles>CC[C@H](C)C(=O)O[C@H]1C[C@H](O)C=C2C=C[C@H](C)[C@H](CCC3C[C@@H](O)CC(=O)O3)[C@H]21</smiles>

Cerivastatin<smiles>COCc1cc(/C=C/[C@H](O)C[C@H](O)CC(=O)O)c(C(C)C)nc1C(C)C</smiles>

\section{Rosuvastatin}<smiles>CC(C)c1nc(N(C)S(C)(=O)=O)nc(-c2ccc(I)cc2)c1/C=C/[C@H](O)C[C@@H](O)CC(=O)O</smiles>

Fluvastatin

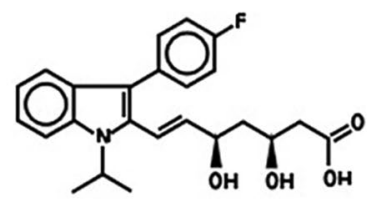

\section{Simvastatin}<smiles>CCC(C)(C)C(=O)OC1C(C)CC2=CC=CC(C)C2C1CCC1C[C@H](O)CC(=O)O1</smiles>

Atorvastatin

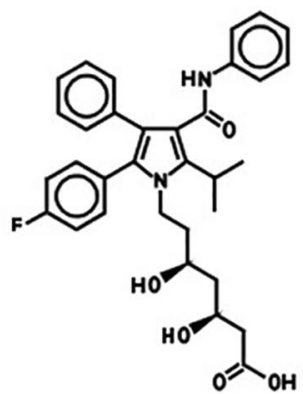

Pravastatin

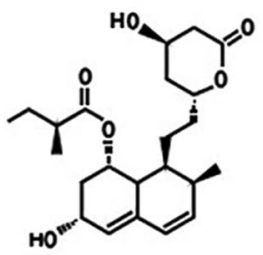

Fig. 1 Chemical structures of selected statins 
well-tolerated, inexpensive, and less toxic than conventional chemotherapy drugs, many researchers considered repurposing statins as a promising strategy for the treatment of cancer.

\section{Anti-tumor effects of statins}

The anti-cancer properties of statins have attracted considerable interest in recent decades [17]. A growing number of population-based studies and interventional clinical trials indicate that statins produce a series of positive anti-cancer effects (Tables 1 and 2) [56-60].

\section{Population-based studies}

In recent years, a large number of population-based observational studies on the anti-tumor effects of statins have been carried out successively (Table 1); most such studies indicate that statins prolong survival and improve prognosis in cancer patients. A 15-year large-scale observational study of a Danish subgroup showed that the use of statins in cancer patients was associated with a reduction in cancer-related mortality (including 13 cancers) compared with patients who did not use statins [61]. Another retrospective study conducted on 146,326 menopausal women in 40 clinical centers in the USA, with an average follow-up time of 14.6 years, showed that people who currently use statins have a significantly lower risk of cancer death (hazard ratio (HR), 0.78; 95\% confidence interval (CI), 0.71-0.86) and all-cause mortality (HR, 0.80; 95\% CI, 0.74-0.88) compared with people who have never used statins [57]. A meta-analysis of 1,111,407 cancer patients showed that the use of statins reduced all-cause mortality and cancer-specific mortality by $30 \%$ and $40 \%$, respectively [58]. Recently, a study involving 303 patients with advanced pancreatic cancer showed that the use of statins (simvastatin and atorvastatin) was associated with increased overall survival in patients [62]. In addition, in patients receiving radiotherapy, surgery and chemotherapy for advanced pancreatic cancer, statin treatment was associated with a 2-year increase in survival, suggesting that statins help improve the outcome of interventions for advanced pancreatic cancer [63]. A meta-analysis of breast cancer studies showed that the overall use of statins was associated with lower cancer-specific and all-cause mortality. Furthermore, while lipophilic statins were found to be associated with lower breast cancer-specific and all-cause mortality, the protective effect of hydrophilic statins on these outcomes was weak, suggesting that the protective effects of statins on breast cancer are affected by the type of statin [64]. However, in another meta-analysis of 7,858 breast cancer cases, no association between statin use and breast cancer risk was observed at a mean follow-up of approximately 5 years [relative risk (RR), 1.02; 95\% CI, 0.89-1.18]
[65]. Given that this conclusion is limited by the relatively short follow-up time of the studies analyzed, further studies are required to investigate the effect of long-term statin use on breast cancer risk. In prostate cancer, a study conducted in 4,204 men who underwent prostate biopsy suggested that people who used statins had a significantly reduced risk (8\%) of prostate cancer compared with people who did not use statins (RR, 0.92; 95\% CI, $0.85-0.98$ ) [22]. Another analysis of 1,001 prostate cancer patients (289 statin users) reported a 0.19 hazard ratio for prostate cancer-specific death among statin users compared with men who did not use statins (95\% CI, 0.060.56) [66]. A recent clinical study showed that statin use is associated with a reduced risk of phosphatase and tensin homolog (PTEN)-negative and fatal prostate cancer [23]. However, the results of a population-based epidemiologic study showed that the use of statins was not associated with overall prostate cancer risk [67], although the credibility of the results of the study are open to question due to the relatively small sample size and the existence of potential selection and recall biases. In gastric cancer, a recent nationwide cohort study suggested that the use of statins is related to a decrease in gastric cancer mortality in the general population, but has no correlation with the incidence of gastric cancer [30]. A recent prospective observational study of ovarian cancer patients conducted in Australia suggested that the increase in patient survival is related to the use of lipophilic statins, but not to hydrophilic statins [59]. In a large-scale population study of 4,913 patients with diffuse large B-cell lymphoma, statins improved the survival rate in a dose-dependent manner [39]. A study of 999 colon cancer patients showed that the use of statins after diagnosis was significantly associated with a lower risk of death from any cause (adjusted RR, 0.67; 95\% CI, 0.51-0.87) and a lower risk of cancer death (adjusted RR, 0.66; 95\% CI, 0.49-0.89) [31]. Similarly, a recent meta-analysis showed that statin use was significantly associated with a decrease in overall mortality and cancer-specific mortality of CRC [32]. In liver cancer, a meta-analysis involving 59,073 patients showed that statin use was significantly associated with a reduced risk of hepatocellular carcinoma ( $\mathrm{HCC}$ ) progression compared with those who did not use statins (RR, 0.54; 95\% CI: 0.47-0.61) [68].

Inconsistencies in observational studies regarding statin use and cancer morbidity and mortality may be due to significant differences in follow-up periods and potential shortcomings in retrospective and observational studies. For example, statin users might be more health-conscious and might see their doctor more frequently than non-users, so non-users are more likely to be diagnosed with cancer at a later stage compared with statin users. In addition, the race diversity of the population in studies 


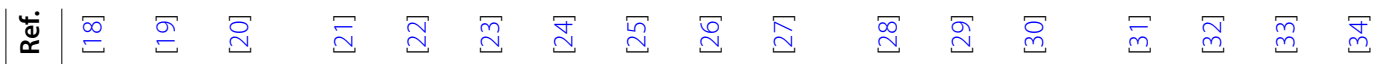

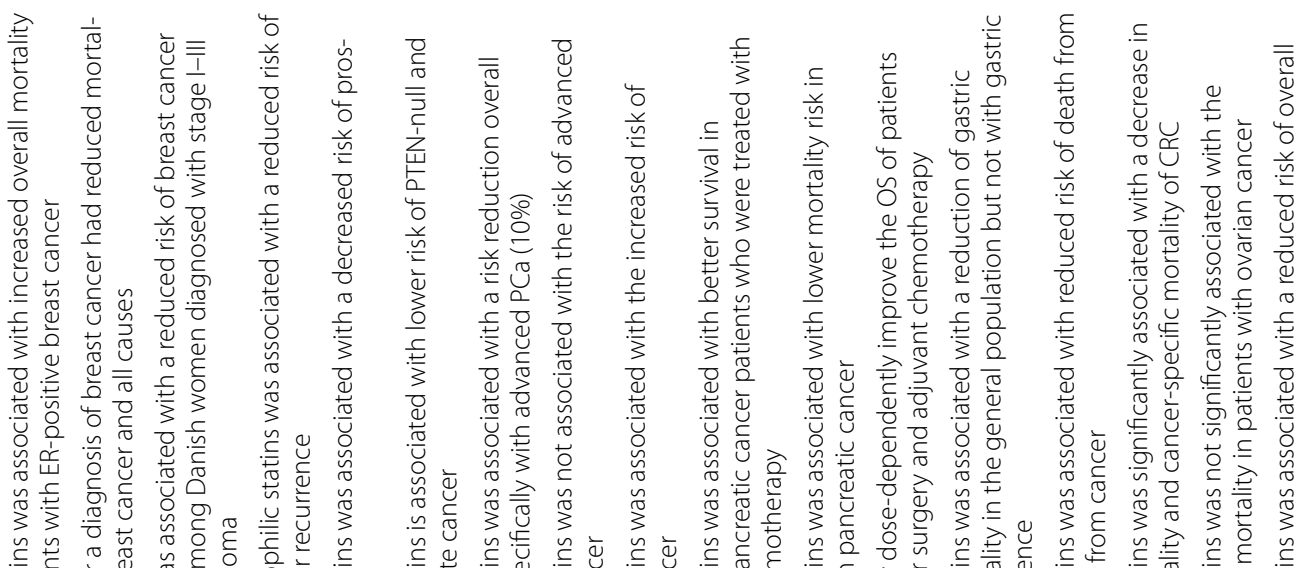

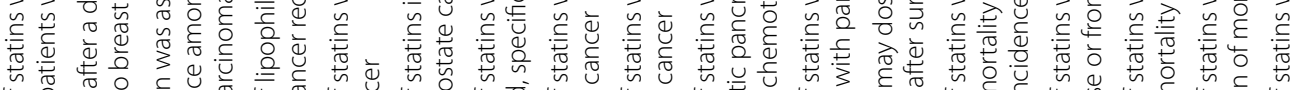

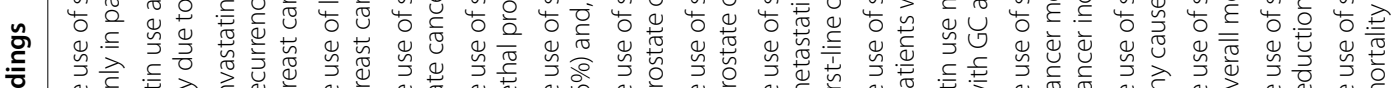

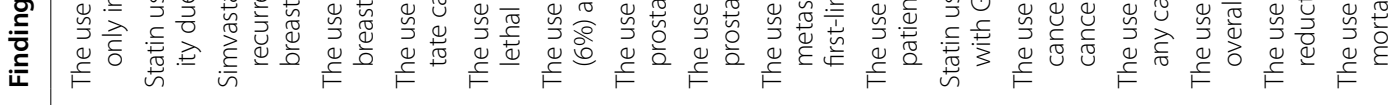
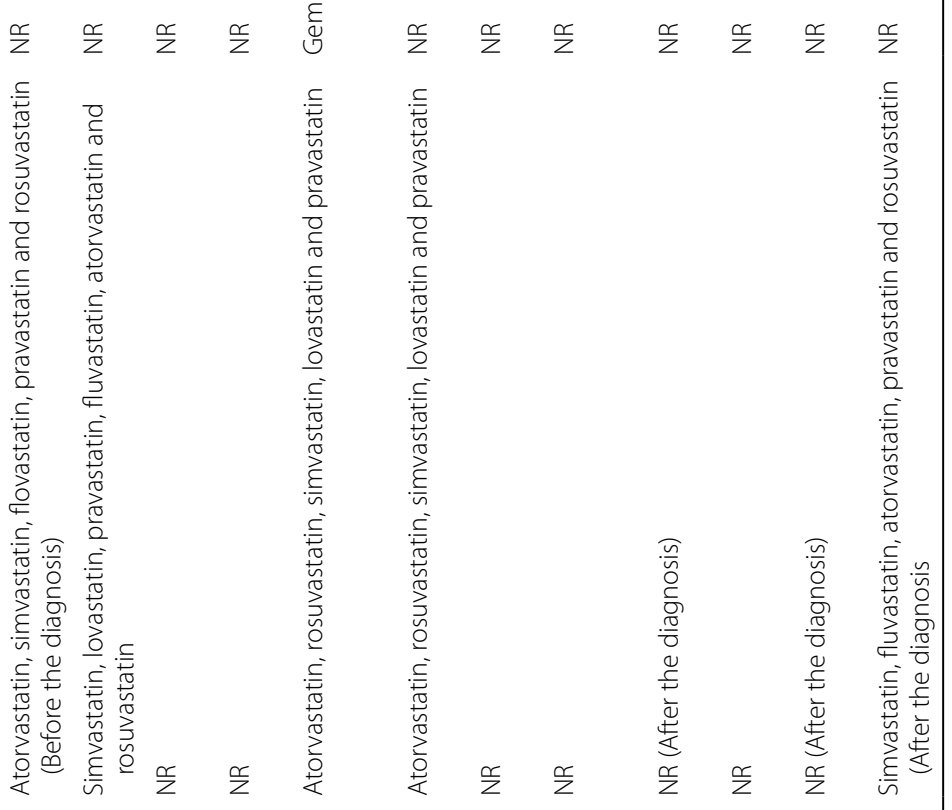


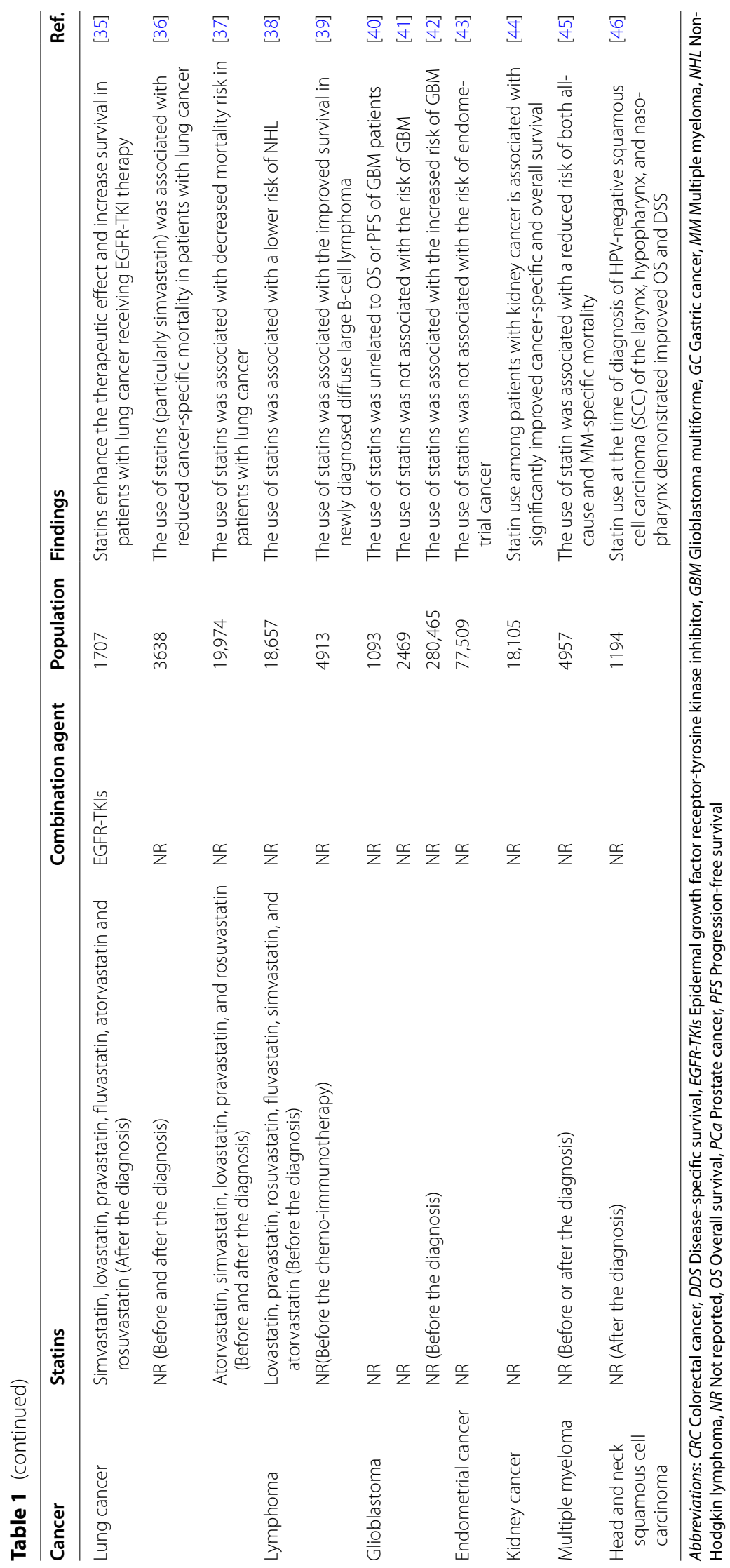


Table 2 Statin use in interventional clinical anticancer studies

\begin{tabular}{|c|c|c|c|c|c|}
\hline Cancer & Statins & Combination agent & Population & Findings & Ref/CTG.ID \\
\hline \multirow[t]{4}{*}{ Breast cancer } & Fluvastatin (After the diagnosis) & NR & 40 & $\begin{array}{l}\text { Fluvastatin decreased breast } \\
\text { tumor proliferation and } \\
\text { increased apoptosis }\end{array}$ & [47] \\
\hline & $\begin{array}{l}\text { Atorvastatin (After the diag- } \\
\text { nosis) }\end{array}$ & $N R$ & 42 & $\begin{array}{l}\text { Atorvastatin decreased breast } \\
\text { cancer proliferation by } \\
\text { influencing the expression of } \\
\text { cyclin D1 and p27 }\end{array}$ & [48] \\
\hline & $\begin{array}{l}\text { Simvastatin (After the diag- } \\
\text { nosis) }\end{array}$ & FAC & 60 & $\begin{array}{l}\text { Simvastatin may improve } \\
\text { the efficacy of FAC in } L A B C \\
\text { patients }\end{array}$ & [49] \\
\hline & $\begin{array}{l}\text { Simvastatin (After the diag- } \\
\text { nosis) }\end{array}$ & NR & 50 & NR & NCT03454529 \\
\hline \multirow[t]{2}{*}{ Prostate cancer } & Fluvastatin (After the diagnosis) & NR & 33 & $\begin{array}{l}\text { Fluvastatin is associated with } \\
\text { promising effects on tumor } \\
\text { cell apoptosis }\end{array}$ & [50] \\
\hline & $\begin{array}{l}\text { Atorvastatin (After the diag- } \\
\text { nosis) }\end{array}$ & ADT & 400 & $\mathrm{NR}$ & NCT04026230 \\
\hline \multirow[t]{2}{*}{ Gastric cancer } & $\begin{array}{l}\text { Simvastatin (After the diag- } \\
\text { nosis) }\end{array}$ & Cisplatin/Capecitabine & 244 & $\begin{array}{l}\text { Adding simvastatin to capecit- } \\
\text { abine-cisplatin did not } \\
\text { increase PFS in patients with } \\
\text { gastric cancer }\end{array}$ & [51] \\
\hline & Pravastatin (After the diagnosis) & ECC & 30 & $\begin{array}{l}\text { Adding pravastatin to ECC } \\
\text { did not improve outcome } \\
\text { in patients with advanced } \\
\text { gastric cancer }\end{array}$ & {$[52]$} \\
\hline \multirow[t]{2}{*}{ Lung cancer } & $\begin{array}{l}\text { Simvastatin (After the diag- } \\
\text { nosis) }\end{array}$ & Gefitinib & 106 & $\begin{array}{l}\text { Simvastatin may improve the } \\
\text { efficacy of gefitinib in that } \\
\text { subgroup of gefitinib-resist- } \\
\text { ant NSCLC patients }\end{array}$ & [53] \\
\hline & $\begin{array}{l}\text { Simvastatin (After the diag- } \\
\text { nosis) }\end{array}$ & Irinotecan/Cisplatin & 62 & $N R$ & NCT00452634 \\
\hline \multirow[t]{3}{*}{ Liver cancer } & Pravastatin (After the diagnosis) & Sorafenib & 312 & $\begin{array}{l}\text { Adding pravastatin to sorafenib } \\
\text { did not improve survival in } \\
\text { patients with advanced HCC }\end{array}$ & [54] \\
\hline & $\begin{array}{l}\text { Atorvastatin (After the diag- } \\
\text { nosis) }\end{array}$ & NR & 240 & NR & NCT03024684 \\
\hline & Pravastatin (After the diagnosis) & TAE/5-FU & 83 & $\begin{array}{l}\text { Pravastatin prolonged the } \\
\text { survival of patients with } \\
\text { advanced HCC }\end{array}$ & [55] \\
\hline Colorectal cancer & $\begin{array}{l}\text { Simvastatin (After the diag- } \\
\text { nosis) }\end{array}$ & Cetuximab//rinotecan & 52 & NR & NCT01281761 \\
\hline Pancreatic cancer & $\begin{array}{l}\text { Simvastatin (After the diag- } \\
\text { nosis) }\end{array}$ & Gemcitabine & 106 & $N R$ & NCT00944463 \\
\hline Ovarian cancer & $\begin{array}{l}\text { Simvastatin (After the diag- } \\
\text { nosis) }\end{array}$ & $N R$ & 20 & NR & NCT04457089 \\
\hline Glioblastoma & $\begin{array}{l}\text { Atorvastatin (After the diag- } \\
\text { nosis) }\end{array}$ & Radiotherapy/Temozolomide & 36 & $N R$ & NCT02029573 \\
\hline Endometrial cancer & $\begin{array}{l}\text { Rosuvastatin (After the diag- } \\
\text { nosis) }\end{array}$ & Megestrol acetate & 43 & $N R$ & NCT04491643 \\
\hline Kidney cancer & $\begin{array}{l}\text { Atorvastatin (After the diag- } \\
\text { nosis) }\end{array}$ & Zoledronate & 11 & NR & NCT00490698 \\
\hline Head and neck cancer & $\begin{array}{l}\text { Atorvastatin (After the diag- } \\
\text { nosis) }\end{array}$ & $N R$ & 414 & $N R$ & NCT04915183 \\
\hline
\end{tabular}

Abbreviations: ADT Androgen deprivation therapy, CRC Colorectal cancer, DDS Disease-specific survival, ECC Epirubicin, cisplatin and capecitabine, EGFR-TKIs Epidermal growth factor receptor-tyrosine kinase inhibitor, FAC Fluorouracil, adriamycin and cyclophosphamide, GBM Glioblastoma multiforme, GC Gastric cancer, HCC Hepatocellular carcinoma, LABC Locally advanced breast cancer, MM Multiple myeloma, NHL Non-Hodgkin lymphoma, NR Not reported, NSCLC Non-small cell lung cancer, OS Overall survival, PCa Prostate cancer, PFS Progression-free survival, TAE Transcatheter arterial embolization, 5-FU 5-fluorouracil 
could be limited. Therefore, it is difficult to determine causality from observational studies. Inconsistent findings highlight the importance of well-designed clinical trials to accurately determine the potential of statins as single- or combination-therapy anticancer drugs.

\section{Interventional clinical trials}

In addition to population-based studies, the ability of statins to kill tumors has also been investigated in several interventional clinical trials (Table 2). A perioperative trial showed that high-dose $(80 \mathrm{mg} /$ day $)$ neoadjuvant fluvastatin decreased breast tumor proliferation and increased apoptosis compared with low-dose $(20 \mathrm{mg} /$ day) treatment [47]. Similarly, another clinical trial in breast cancer patients treated with a high dose of atorvastatin $(80 \mathrm{mg} /$ day $)$ in the first 2 weeks before surgery suggested that this treatment decreased breast cancer proliferation by influencing the expression of cyclin D1 and p27 [48]. Recently, Longo et al. revealed that neoadjuvant fluvastatin treatment prior to radical prostatectomy may be effective in inducing intratumoral apoptosis in patients with localized prostate cancer [50].

Statins have also been shown exert antitumor effects by enhancing the response of combination therapy. Recently, Yulian et al. found that simvastatin combined with FAC (Fluorouracil, adriamycin and cyclophosphamide) improved the response to neoadjuvant chemotherapy in patients with advanced local breast cancer [49]. Cantini et al. found that high-intensity statins enhanced the clinical activity of programmed death receptor-1 (PD-1) inhibitors in patients with malignant pleural mesothelioma and advanced non-small cell lung cancer [69]. Han et al. found that simvastatin may improve the efficacy of gefitinib in gefitinib-resistant non-small cell lung cancer (NSCLC) patients [53]. Kawata et al. reported that pravastatin prolonged survival in patients with advanced HCC who received 5-fluorouracil (5-FU) treatment after transcatheter arterial embolization (TAE) [55]. However, Jouve et al. found that adding pravastatin to sorafenib did not improve survival in patients with advanced HCC [54]. Similarly, Kim et al. found that adding simvastatin to capecitabine-cisplatin did not increase PFS in patients with gastric cancer [51]. Konings et al. also found that adding pravastatin to ECC (epirubicin, cisplatin and capecitabine) did not improve outcome in patients with advanced gastric cancer [52].

In summary, the anti-cancer properties of statins have been demonstrated in several clinical and epidemiological studies. However, these effects are not consistent and in several clinical studies, statins were not associated with a reduction in cancer mortality and morbidity, with some even suggesting the opposite effect. Therefore, the anticancer properties of statins require further exploration of mechanism of action to maximize design of experiments for further validation in clinical trials.

\section{Anti-cancer mechanisms of statins}

The anticancer properties of statins have been demonstrated in many preclinical and clinical studies. Therefore, the mechanism underlying the anti-cancer effect of statins has aroused widespread interest. The many anticancer mechanisms of statins that have been proposed in recent years are summarized in Fig. 2 and Table 3.

\section{The mevalonate pathway}

Metabolic changes are a hallmark of cancer cells [135]. However, it has always been a challenge to identify drugs that target multiple tumor types and cancer-specific

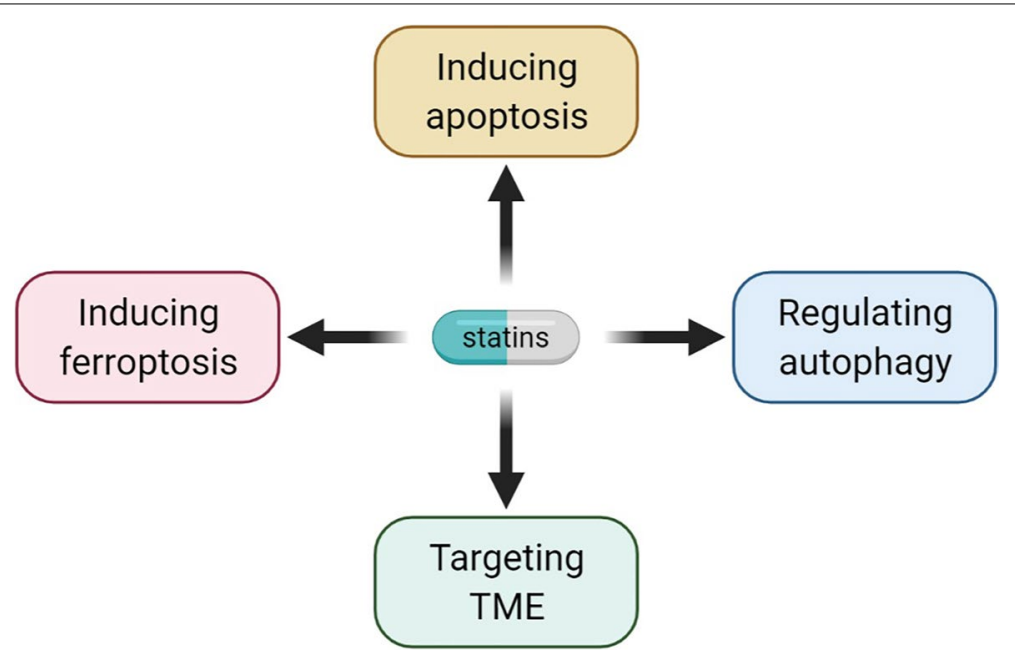

Fig. 2 Statin targets in cancer therapy 


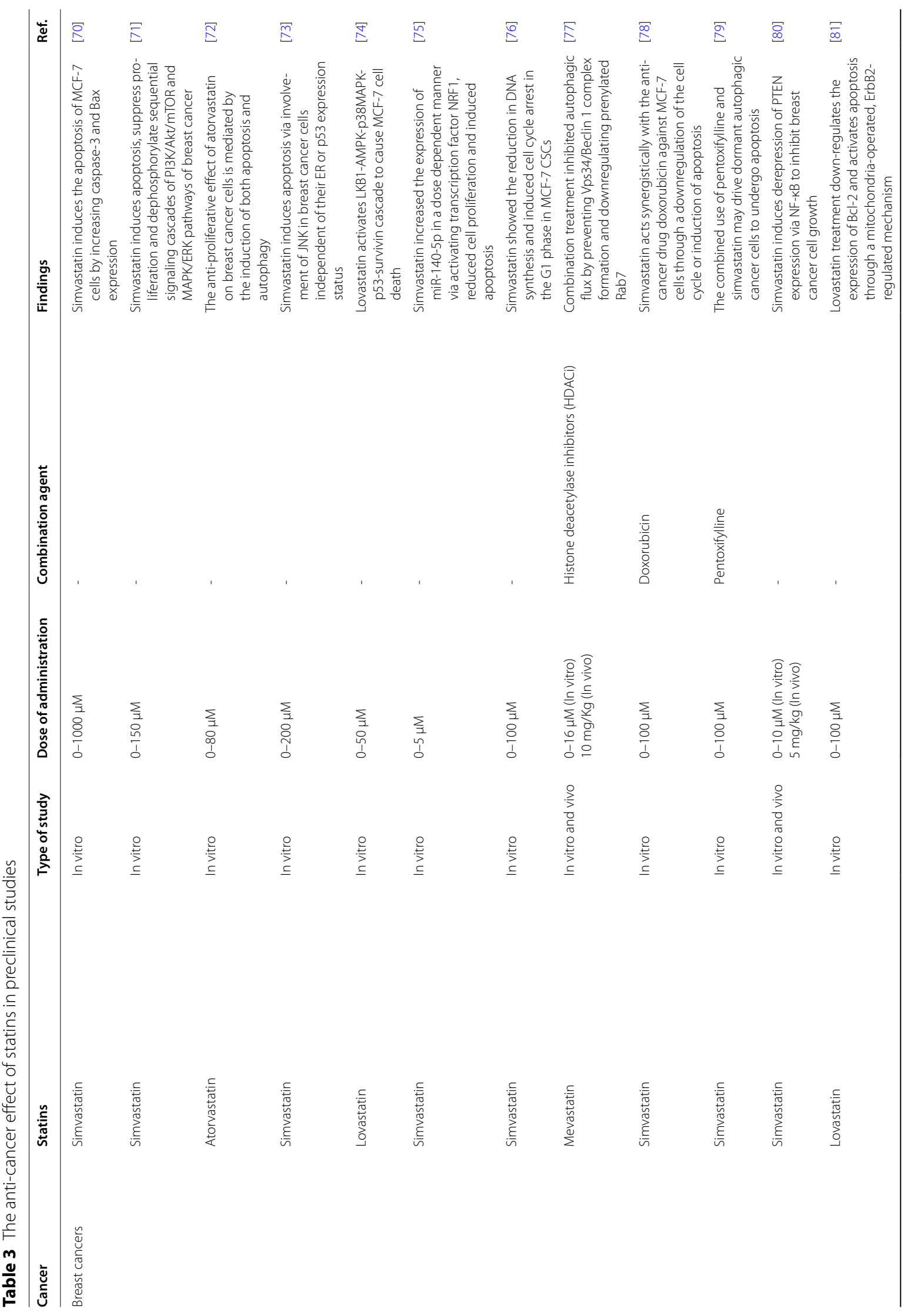




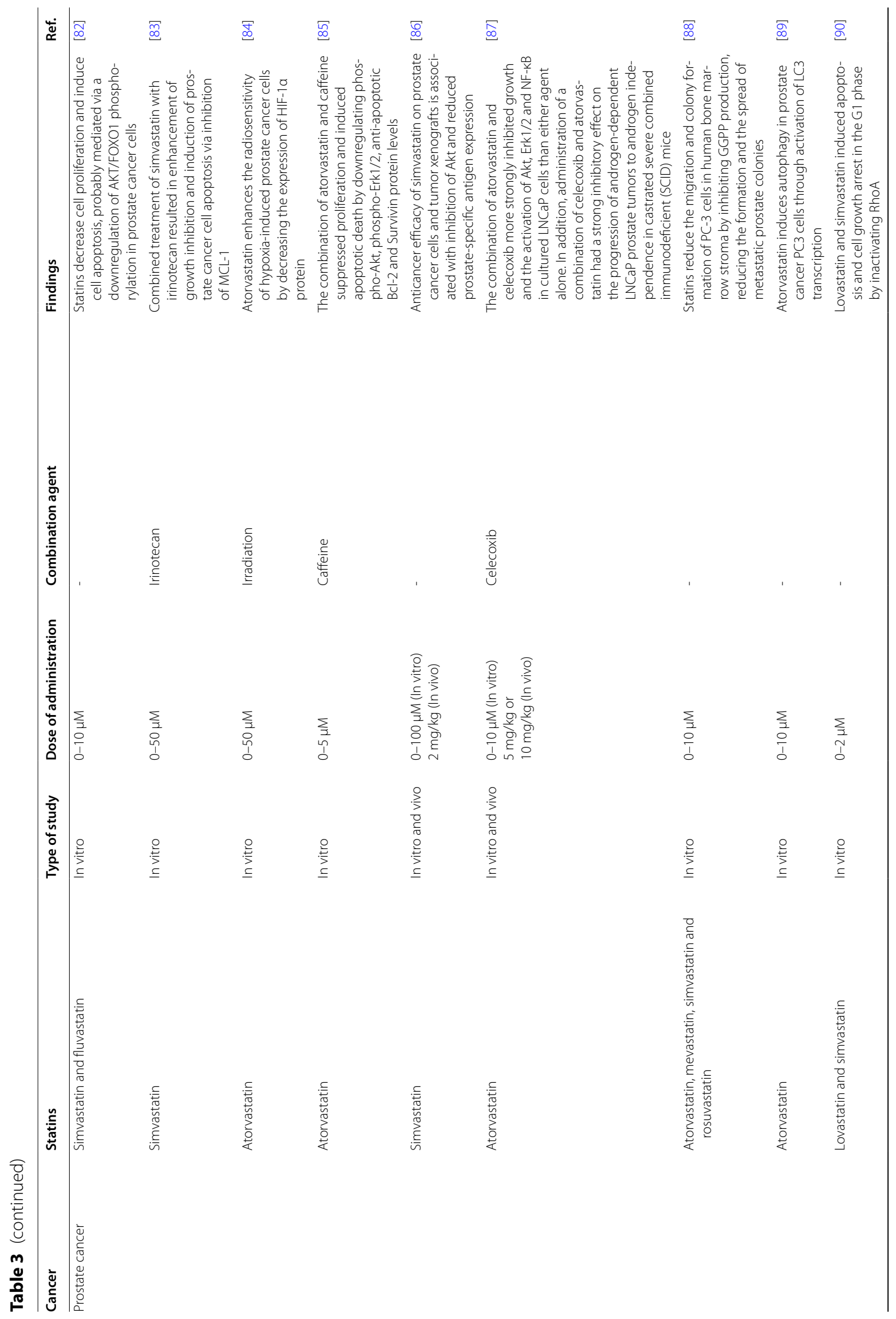




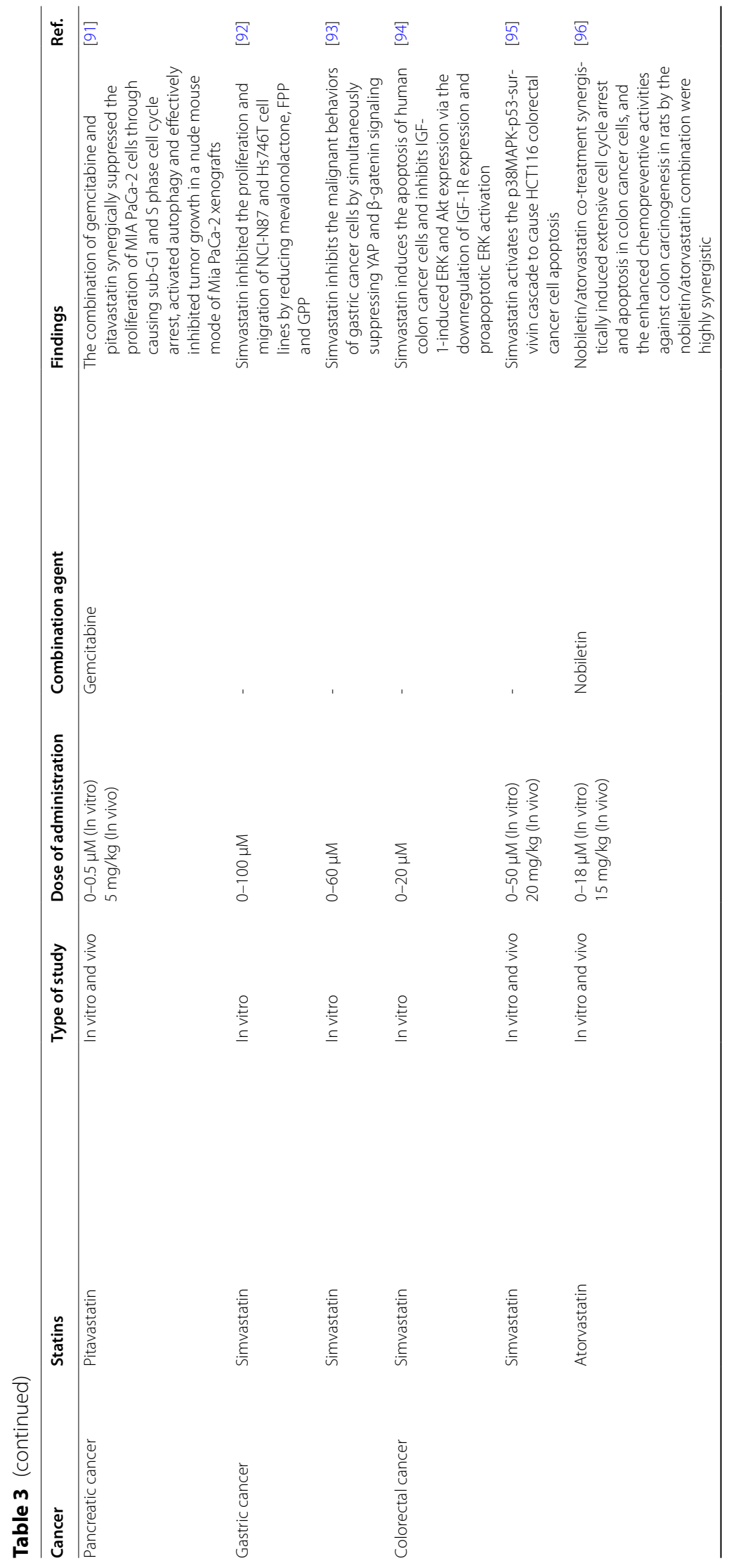




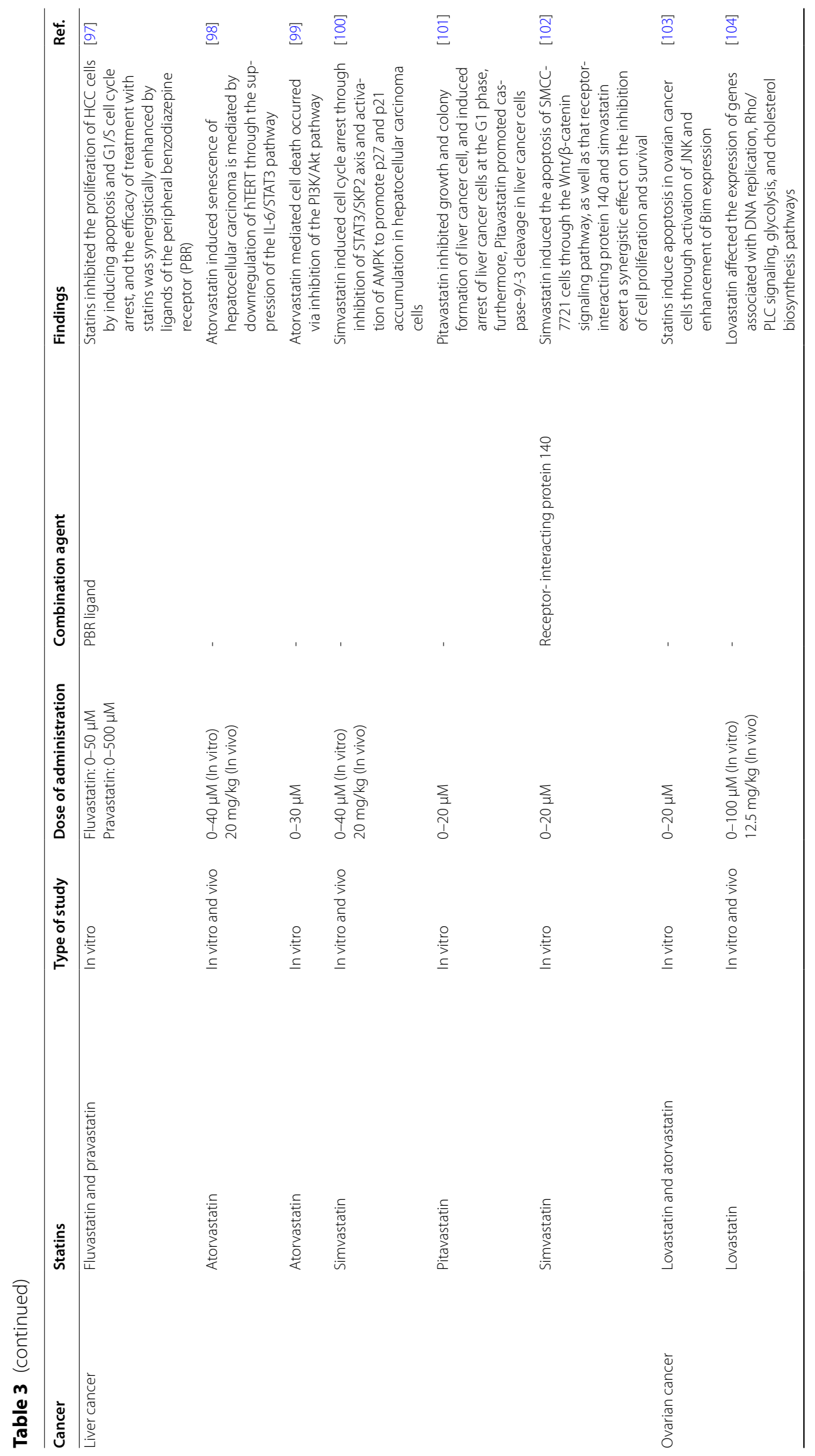




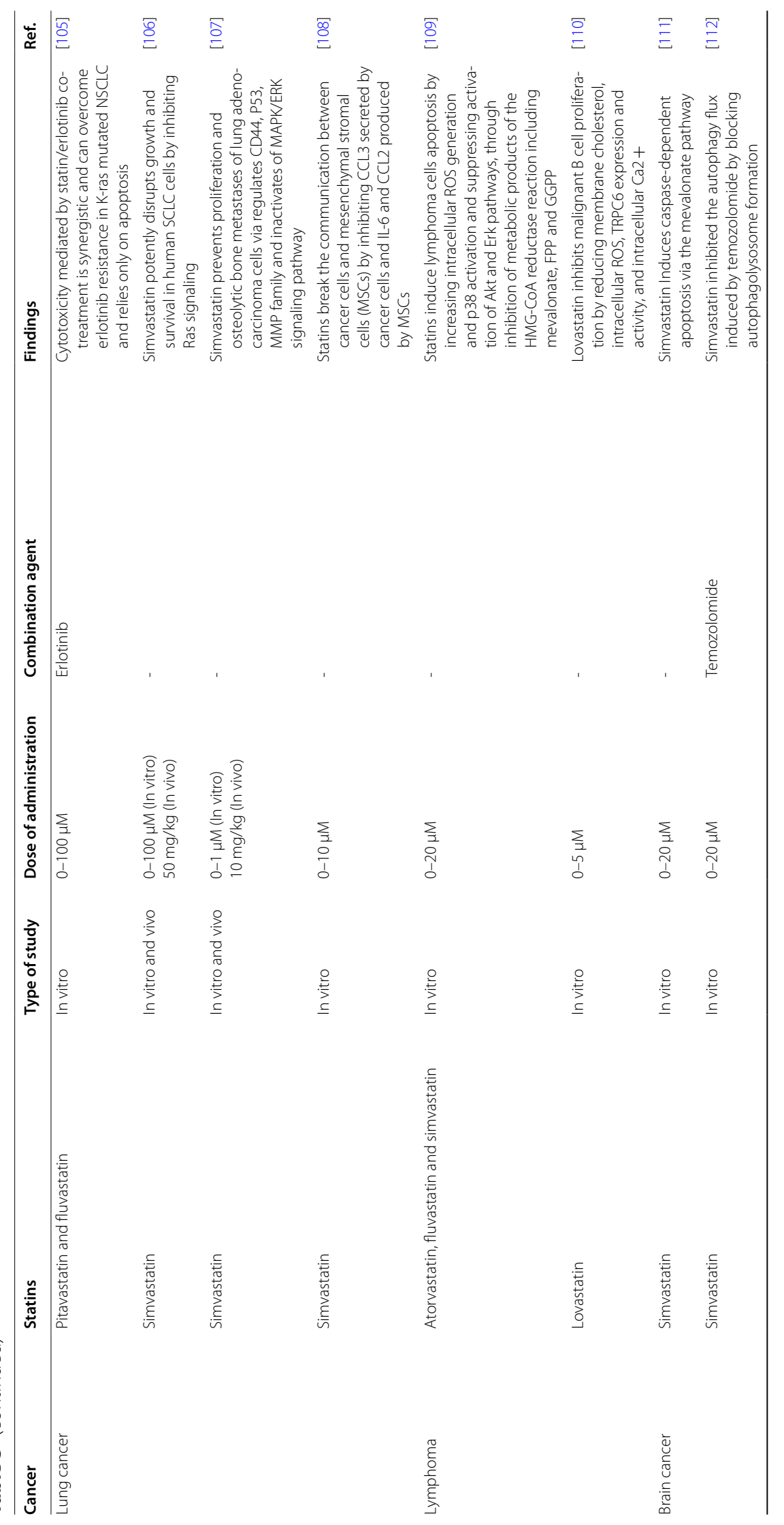




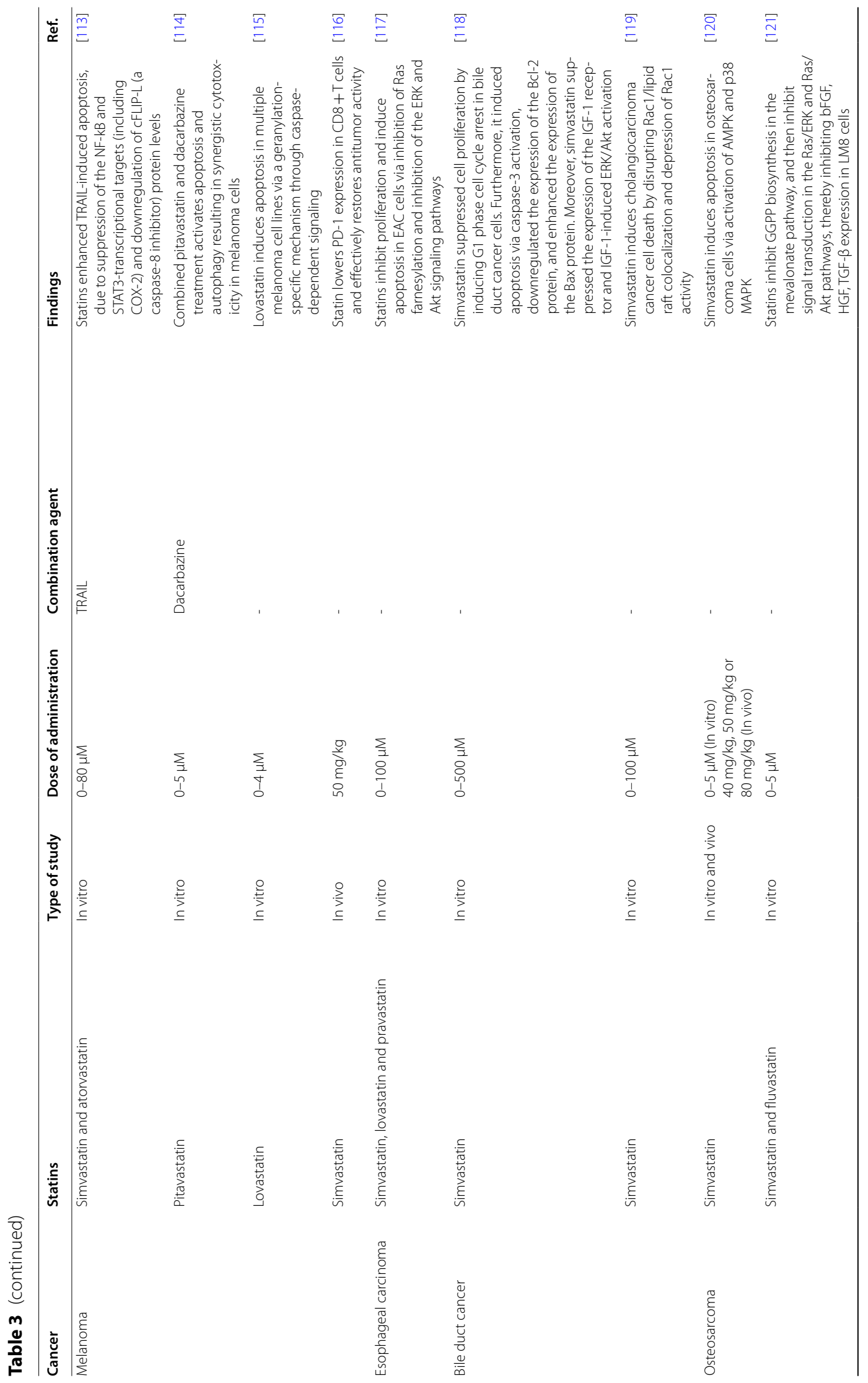




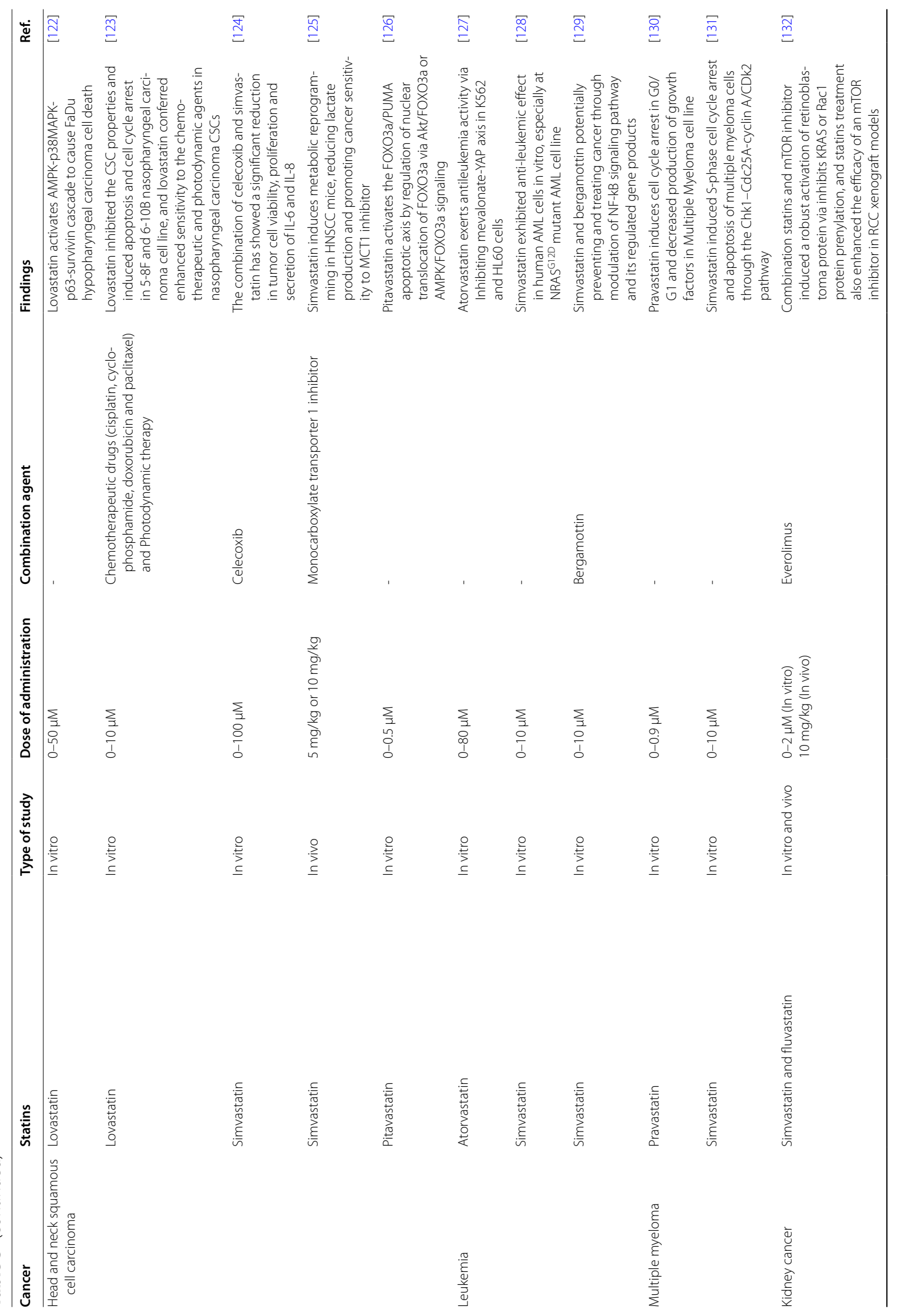




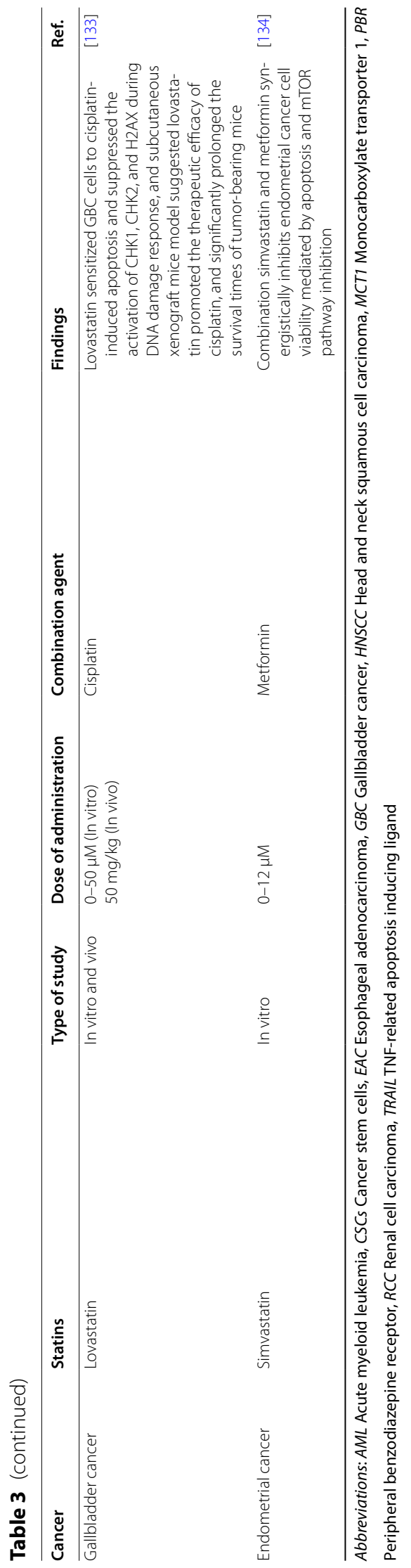




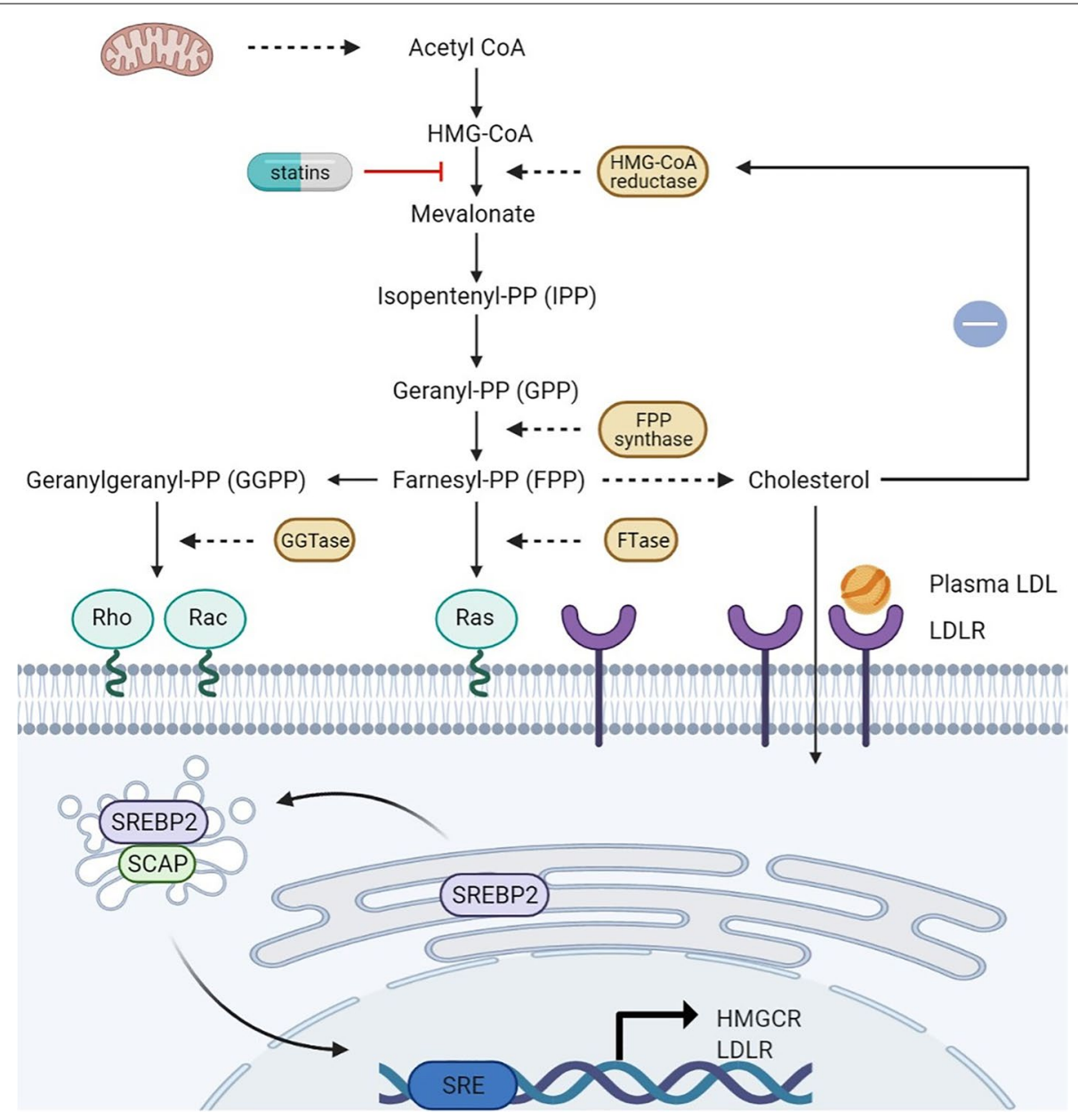

Fig. 3 The mevalonate pathway and its transcriptional regulation. The mevalonate pathway begins with the end-product of glycolysis, acetyl-CoA, which is metabolized through several enzymatic steps to mevalonate, IPP, GPP, FPP, GGPP and cholesterol. Both FPP and GGPP can be post-translationally added to proteins, especially small monomeric GTPases (such as Ras, Rho, or Rac). Cholesterol is produced by cells via the mevalonate pathway or LDLR-mediated LDL endocytosis from the serum. When intracellular cholesterol levels are low, SCAP mediates the translocation of SREBP2 to the Golgi apparatus, where it is cleaved by proteases. The active N-terminal fragment is released and translocated to the nucleus, where it binds to the SRE regions of the HMGCR and LDLR promoters to induce gene expression. The inhibitory feedback mechanism mediated by cholesterol is indicated in blue. The mevalonate pathway can be blocked by statins

metabolic dependence. The mevalonate pathway is an important and complex signaling pathway for the production of various isoprenoids, such as cholesterol, vitamin D, lipoproteins, polyol and ubiquinone [136]. Accumulating evidence indicates that mevalonate pathway (Fig. 3) flux, which is an absolute requirement for all cells, is increased in carcinogenic lesions and is a general feature of cancer [137]. This increased demand for mevalonate is a hallmark of tumorigenesis, and the increased availability of mevalonate pathway intermediates leads to adaptive changes that promote the adaptability of tumor cells [138]. A central motivation for targeting the mevalonate pathway is that selective and well-tolerated inhibitors already exist. Statins block HMGCR synthesis of mevalonate and are prescribed for the treatment of hypercholesterolemia in millions of people. Moreover, numerous in vivo and in vitro studies have shown that statins exert anti-cancer properties by inhibiting the mevalonate pathway. Here, we further divide these effects into those that are induced via non-cholesterol-mediated pathways and cholesterol-mediated pathways.

\section{Non-cholesterol-mediated pathways}

The mevalonate pathway starts with acetyl-CoA, which is derived from the decarboxylation of pyruvate, the final product of glycolysis. Three molecules of acetyl$\mathrm{CoA}$ are then condensed into 3-hydroxyglutaryl-CoA, which is converted to mevalonate by HMGCR [139] in 
a reaction that represents the rate-limiting step in this pathway. Mevalonate is then phosphorylated by mevalonate kinase and metabolized to isopentenyl pyrophosphate (IPP) [140-142], which is the factor that defines the key role of the mevalonate pathway in the synthesis of farnesyl pyrophosphate (FPP) and geranylgeranyl pyrophosphate (GGPP) via reactions that are catalyzed by farnesyl diphosphate synthase (FDPS) and GGPP synthase (GGPPS) [141, 143]. FPP is the basic component required for the production of squalene, which is a precursor of cholesterol and a key product of the mevalonate pathway. Cholesterol is mediated by additional enzymes, such as squalene epoxidase and squalene synthase [144, 145]. Cholesterol plays a vital role in the establishment and maintenance of the structure and function of cellular membranes. It is also a precursor of steroid hormones, vitamin D and bile acids [146, 147]. In addition, cholesterol is essential for the biogenesis of lipid rafts composed of lipids and proteins. These dynamic assemblies float within the cell membrane and participate in membrane transport, signal transduction, and cell polarization [148]. The synthesis of FPP and GGPP is essential for the post-translational modification referred to as prenylation of various proteins. This reaction is mediated by farnesyltransferase (FTase) I and geranyltransferases (GGTases) I and II. The localization, membrane anchoring and function of hundreds of signaling proteins depend on post-translational prenylation $[139,149]$. These proteins include small monomeric GTPases (guanosine-triphosphate hydrolase) (e.g. Ras, Rho or Rac) and the $\gamma$-subunit of G-protein coupled receptors, which are involved in numerous important intracellular signaling pathways [150]. These small monomeric GTPases promote their anchoring and activation on the plasma membrane through isoprenylation and association of these signaling molecules with effectors to regulate a wide range of cellular functions, such as endocytosis/exocytosis, differentiation, cytoskeletal rearrangement and contraction, migration, apoptosis, and proliferation [151, 152]. Inhibition of HMGCR by statins depletes the pools of mevalonate (MA), IPP, FPP and GGPP in cells. This process interferes with the function of Ras and Rho family GTPases [153-157]. Indeed, lower GGPP and FPP concentrations, leading to reduced RAS and Rho isoprenylation, signal transduction, and DNA synthesis, are important functional consequences of statins in the treatment of cancer [119, 158-162]. Inhibiting the farnesylation of these proteins restricts their activity and might hinder cancer cell proliferation [163, 164]. Studies have shown that the inhibitory effect of simvastatin on the proliferation, migration and invasion of the gastric cancer cell lines MKN45 and MGC803 is due to a reduction in GGPP and RhoA activity mediated by inhibition of $\beta$-catenin and the Yes-associated protein (YAP) signaling pathways. Statins activate the intrinsic apoptotic pathway by disrupting the prenylation of key regulatory proteins. Therefore, the depletion of isoprenoids leads to the apoptosis of a variety of cancer cells $[112,165]$. Simvastatin has also been shown to significantly inhibit the proliferation and migration of two cell lines of intestinal (NCI-N87) and diffuse (Hs746T) metastatic gastric tumor histological subtypes. Furthermore, the anti-proliferative effects of simvastatin in gastric cancer cells were reversed by the addition of mevalonate, FPP and GPP [92]. Simvastatin also activates caspase-3/-7/-9, which in turn induce apoptosis in human cancer cell lines through depletion of isoprenoids, a precursor to the prenylation of the small Rho GTP-enzyme $[73,166]$. Fujiwara et al. reported that statins promote cell death by increasing the activation of caspases-3/-9, inducing $\mathrm{Bcl}-2$ interacting mediator of cell death (Bim) expression, arresting the cell cycle at the G1 phase, and by decreasing the mitochondrial membrane potential $(\Delta \psi \mathrm{m})$ through inhibition of Ras/ERK and Ras/mTOR pathways [167]. Statins stimulate membrane FasL expression and lymphocyte apoptosis via the RhoA/Rhoassociated protein kinase (ROCK) pathway in murine melanoma cells in vitro [168]. A recent study showed that statins inhibit pyrimidine nucleotide biosynthesis by inhibiting the mevalonate pathway, and also induce oxidative stress and apoptosis in p53-deficient cancer cells [169]. Statin-induced GGPP depletion blocks macropinocytosis and starves cells with oncogenic defects [170]. Lovastatin-induced MCF-7 cancer cell death is mediated via the liver kinase B1 (LKB1)-AMP-activated protein kinase (AMPK)-p38 mitogen-activated protein kinase (p38MAPK)-p53-survivin signaling cascade [74]. Yin et al. found that pituitary tumor-transforming gene 1 (PTTG1) was significantly overexpressed in malignant breast cancer cell lines, and simvastatin downregulates its expression by inhibiting GGPP [171]. Freed-Pastor et al. revealed that mutant p53 can disrupt mammary acinar morphology by up-regulating the mevalonate pathway, thereby exerting a carcinogenic effect, while statins inhibit the mevalonate pathway to exert a tumor suppressor effect [172]. Epithelial-to-mesenchymal transition (EMT), which is an effective mechanism of cancer metastasis, is a dynamic multi-gene programming cycle [173]. Lipophilic statins have been found to function as antagonists of EMT signaling pathways in stem-like cells in breast cancer by inhibiting the mevalonate pathway [174]. In prostate cancer, lovastatin and simvastatin inactivate RhoA, thereby inducing cell apoptosis and cell cycle arrest in the G1 phase [90].In ovarian cancer, statins promote cell apoptosis in a dosedependent manner via a GGPP-mediated mechanism 
[175]. Accumulating evidence shows that statins inhibit tumor metastasis by disrupting geranylgeranylation and farnesylation of small GTPases [160, 176-178]. These findings support the view that statins may be promising anti-cancer drugs.

\section{Cholesterol-mediated pathways}

A link between cellular cholesterol levels and cancer was first reported a century ago [179]. Since then, several studies have shown that cholesterol levels in tumors are elevated compared to those in normal tissues $[180,181]$.

Variation in the mechanisms by which tumor cells increase intracellular cholesterol have been observed, including increased expression of low-density lipoprotein receptor (LDLR) or insufficient feedback regulation of LDL [182-188]. Cholesterol promotes the progression of sex hormone-responsive breast cancer and prostate cancer by providing estrogen and androgens [189]. In addition, cholesterol is very important for cell proliferation and the cell cycle, especially for progression to S-phase [190], and plays a central role in lipid rafts. Cancer cells have an increased requirement for cholesterol and contain more lipid rafts than normal cells to meet the need for tumor-promoting cell signaling proteins [147]. Cells acquire cholesterol from plasma via LDLR-mediated endocytosis, or synthesize cholesterol de novo via the mevalonate pathway. The discovery of sterol regulatory element binding proteins (SREBPs) is a breakthrough in understanding the regulation of mevalonate pathway genes. These transcription factors are synthesized as inactive precursors on the endoplasmic reticulum membrane, where they bind to SREBP cleavage activating proteins (SCAPs), which function as sterol sensors. SREBP-2 is transported to the Golgi apparatus by SCAPs when intramembranous cholesterol levels are reduced. SREBPs are cleaved by two proteases in the Golgi apparatus, and then their active fragments are released and translocated to the nucleus, where they bind to the sterol regulatory elements (SRE) in the promoter regions of the $H M G C R$ and $L D L R$ genes to induce their expression. Transcriptional activation of HMGCR leads to the de novo biosynthesis of cholesterol via the mevalonate pathway. After $L D L R$ transcription is activated, receptor-mediated endocytosis of low-density lipoprotein leads to increased cellular cholesterol uptake. When the intracellular cholesterol level is high, SCAPs prevent the translocation and activation of SREBPs, resulting in the transcriptional inactivation of $H M G C R$ and $L D L R$ [191-194]. The complexity of these precisely controlled regulatory mechanisms ensures that cholesterol homeostasis is maintained within cells [195]. Dysregulation of cholesterol homeostasis or key molecules in cholesterol are not only related to several well-known carcinogenic pathways, but also related to inflammasome- and miRNA-mediated cancer development. SREBP2 not only regulates the transcriptional activity of cholesterol biosynthesis genes and LDLR-mediated cholesterol influx, but also regulates the transcriptional activity of Nodlike receptor protein 3 (NLRP3) inflammasome-related inflammation. The causal relationship between chronic inflammation and cancer is widely established. Inflammasomes, which are large intracellular multi-protein signaling complexes formed in response to inflammation, participate in the activation of inflammatory protease caspase- 1 and the pro-inflammatory cytokines interleukin (IL)-1 $\beta$ and IL-18 [196]. NLRP3 regulation is closely related to the development and progression of tumors, including head and neck squamous cell carcinoma [197], colorectal cancer [198] and breast cancer [199]. MicroRNA 33 (miRNA33) binds to the SREBP2 gene to positively regulate SREBP2 expression. Hyperactivation of cholesterol biosynthesis leads to uncontrolled cell growth [200].

Newly synthesized free cholesterol is transported to subcellular membranes by cholesterol transfer protein; however, to avoid excessive accumulation of free cholesterol, surplus cholesterol is esterified by acylCoA:cholesteryl acyltransferase 1 (ACAT1) to form cholesteryl esters (CEs), which are stored as lipid droplets (LDs) in cells [201]. Although CEs serve as a cholesterol reservoir, the accumulation of CEs or ACAT1 overexpression promote tumorigenesis. In a xenograft model of glioblastoma, ACAT1 ablation was shown to reduce tumor progression [202]. ACAT1 overexpression was also found in hepatocellular carcinoma [203]. In addition, the migration ability of breast cancer cells and the progression of prostate cancer was found to be suppressed by inhibiting the expression of ACAT1 [204, 205]. When de novo biosynthesis is the main source of intracellular cholesterol, most cells acquire cholesterol from LDL in the circulatory system via LDLR-mediated endocytosis [206]. Proprotein-convertase-subtilisin-kexin type-9 (PCSK9) overexpression promotes lysosomal degradation of LDLR [207], leading to hypercholesterolemia and ultimately, the occurrence of hepatocellular carcinoma [208]. Excess cholesterol also produces oxysterols, which are natural ligands for liver X receptors (LXRs). The binding of cholesterol to LXRs triggers conformational changes of the receptor, thereby enhancing the interaction with the co-activator protein and promoting the transcription of cholesterol efflux-related genes [209], including ATPbinding cassette $(A B C)$ subfamily A member 1 (ABCA1), $A B C$ subfamily $G$ member 1 (ABCG1) and ABCG5/8. The excess cholesterol can be exported to lipid-poor apolipoprotein A-I (ApoA-I) via ABCA1 or ABCG1, and generate high-density lipids proteins (HDLs), which are 
transported back to the liver [210-213]. When the intracellular cholesterol level is high, the LXR can upregulate $A B C A 1$ transcription [213]. However, in cancer cells, ABCA1 expression is inhibited via the phosphatidylinositol-3-kinase (PI3K)/protein kinase B (AKT)/mechanistic target of rapamycin complex 1 (mTORC1) pathway [200]. MiR-183 promotes the proliferation and anti-apoptotic properties of colon cancer cells by directly degrading ABCA1 mRNA to maintain high levels of intracellular cholesterol [214]. Similarly, miR-27a-3p also inhibits cancer cell apoptosis by blocking cholesterol efflux or targeting ABCA1 [215]. LXR overexpression has been shown to have anti-proliferative effects in gastric cancer cells [216]. Cholesterol and its oxygenated derivatives bind with high affinity to the G protein-coupled receptor (GPCR) known as smoothened receptor (SMO), which activates the Sonic Hedgehog (SHH) pathway [217]. The SHH pathway is considered to be an oncogenic signaling cascade based on its ability to promote cell cycle progression and stem cell proliferation by increasing glioma-associated oncogene homolog 1 (GLI1) activity, which subsequently activates hedgehog targeting genes, thereby enhancing tumor formation [218]. Statins arrest SHH signaling in medulloblastoma cells and fibroblasts by inhibiting cholesterol synthesis, thus attenuating tumor proliferation [219]. Similarly, Fan et al. recently found that statins suppress medulloblastoma growth without bone toxicity by repressing hedgehog signaling in tumor cells [220]. These studies illustrate the inseparable correlation between cholesterol and cancer, and reveal that statins exert anticancer properties by inhibiting the de novo synthesis of cholesterol.

\section{Statins regulate autophagy}

Both autophagy and apoptosis are important biological phenomena involved in various processes such as development and growth. The major distinction between autophagy and apoptosis is their purpose. For example, during stress conditions, autophagy primarily targets certain toxic components to preserve cell survival [221, 222]. When autophagy is insufficient to reduce stress and compensate for cellular damage, this results in autophagic cell death, which is similar to apoptosis [223, 224]. Since the discovery of autophagy, numerous studies have shown that autophagy is associated with the progression of pathological conditions, especially cancer [225-227]. Autophagy has been shown to reduce the viability of tumor cells or play a protective role in cancer. Thus, autophagy seems to play a dual role in tumorigenesis and tumor progression [228]. The tumor-suppressive function of autophagy is primarily important in the early stages of cancer development, representing a critical quality control mechanism that maintains genomic integrity by regulating the degradation of damaged proteins or organelles (such as dysfunctional mitochondria) [228, 229]. Autophagy also facilitates oncogene-induced senescence [230] and contributes to cancer immune surveillance [231]. The tumor-promoting effects of autophagy are exerted mainly in the later stages of tumor development. Due to the rapid proliferation of cancer cells, the nutritional requirements for anabolic pathways are high. Autophagy contributes to cancer cell metabolism by recycling cellular substrates [232]. Autophagy also promotes the survival of cancer cells under stress conditions, such as tumor hypoxia, nutrient deprivation or endoplasmic reticulum (ER) stress [233, 234]. In summary, interfering with autophagy is a reasonable therapeutic strategy to improving the effect of anti-cancer treatments in the clinic.

A variety of anti-cancer drugs have been developed based on their ability to regulate autophagy. The first report of statin-induced autophagy showed that hydrophobic statins, such as simvastatin, induced autophagy in rhabdomyosarcoma A204 cells [235] through depletion of the GGPP pool [236]. After deletion of the autophagy-related gene 5 (ATG5) or ATG7 gene in SPC-A-1 cells, fluvastatin inhibits bone metastasis by inducing autophagy in lung adenocarcinoma cells [237]. In HEK293 human embryonic kidney cells, atorvastatin induces autophagy in a mevalonate (MEV) pathway-dependent manner by inhibiting GGPP synthesis [89]. Autophagy was induced in U251 cells by treatment with simvastatin for $24 \mathrm{~h}$, and this effect was reversed by the addition of MEV, which again suggests that the MEV cascade is involved in statin-mediated autophagy [238]. In human leukemia cells treated with simvastatin for $24-72 \mathrm{~h}$, the induction of autophagy flux appeared to be mediated by the inhibition of cholesterol production, rather than the synthesis of FPP or GGPP [239]. Atorvastatin induced autophagy in the Huh7 and HCT116 gastrointestinal tumor cell lines independent of the MEV pathway [240]. Simvastatin can impair autophagy flux and induce breast cancer cell death by stimulating the extracellular regulated protein kinases 1 and 2 (ERK1/2) and Akt pathways [79]. Lovastatin stimulates autophagy through the Rac/phospholipase C/inositol 1,4,5-triphosphate axis, and markedly decreases the viability and migration ability of malignant pleural mesothelioma tumor cells [241]. Due to the resistance of tumor cells to apoptosis-based therapy, and the stimulatory effect of cancer cell apoptosis on the survival and proliferation of neighboring cells, the induction of autophagic cell death is preferred to apoptosis as a strategy to combat cancer. Studies have shown that the combination lovastatin and farnesyltransferase inhibitors can stimulate non-apoptotic 


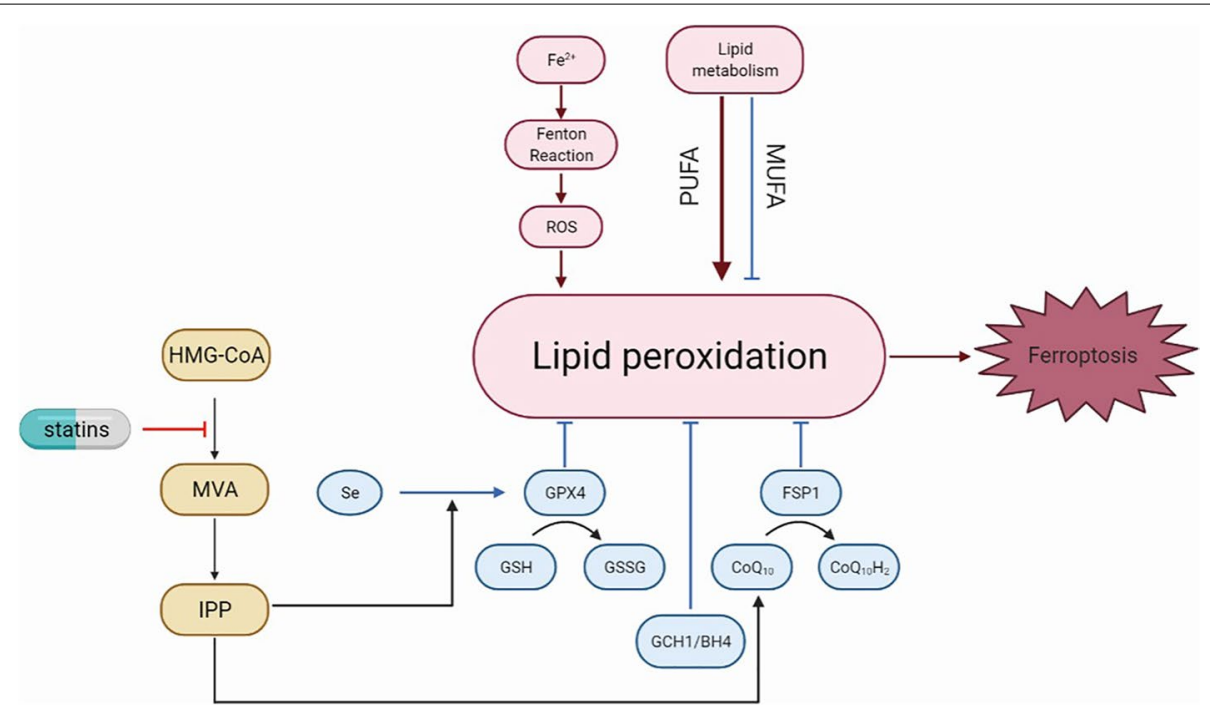

Fig. 4 The relationship between statins and ferroptosis. Iron overload, lipid reactive oxygen species (ROS) accumulation, and lipid peroxidation are prerequisites for the activation of cell death by ferroptosis. Ferroptosis is governed by three antioxidant axes, i.e., the GSH/GPX4, FSP1/CoQ10/ $\mathrm{NAD}(\mathrm{P}) \mathrm{H}$ and $\mathrm{GCH} 1 / \mathrm{BH} 4$ axes. The FSP1/CoQ10/NAD(P)H axis relies on the mevalonate pathway to generate CoQ10. IPP, the precursor of CoQ10, is also a limiting substrate for enzymatic isopentenylation of Sec-tRNA, thereby influencing the expression of GPX4. Statins regulate the GSH/GPX4 and FSP1/CoQ10/NAD(P)H axes via the mevalonate pathway, thereby inducing cell death by ferroptosis

cell death and impair autophagy flux [242]. Angiogenesis plays a critical role in cancer progression. Atorvastatin stimulates autophagy in human umbilical vein endothelial cells. Furthermore, high-dose atorvastatin activates apoptosis and inhibits angiogenesis. Atorvastatin stimulates autophagy through upregulation of light chain 3-phosphatidylethanolamine conjugate (LC3II), which effectively reduces proliferation and viability of cancer cells [243]. The benefits of statins as adjuvant therapy for cancer have been widely reported. The combination of lovastatin and cisplatin has been found to enhance expression of the autophagy marker LC3B-II and decrease the viability of cancer cells through the induction of autophagic cell death [244]. Autophagy has been shown to play a central role in the induction of chemotherapeutic resistance [245, 246]. The anti-cancer effects of the chemotherapeutic agent temozolomide (TMZ), which is used to treat glioblastoma (GBM), are markedly reduced by TMZinduced autophagy. A recent study showed that simvastatin inhibits the autophagic flux induced by TMZ by blocking autophagolysosome formation, thereby sensitizing glioblastoma cells to TMZ-induced cell death [112]. However, a recent study showed that atorvastatin reduces cell viability and promotes cervical cancer cell apoptosis by inducing the activation of caspase-3 and poly (ADP-ribose) polymerase (PARP) and upregulating Bim. However, atorvastatin induced cellular autophagy in cervical cancer cells, and pharmacologic inhibition of autophagy using autophagy inhibitors remarkably enhanced atorvastatin-induced apoptosis of cervical cancer cells [247].

In summary, statins are capable of modulating autophagy, making them promising candidates for the treatment of cancer. However, the regulatory effects of statins on autophagy require further clarification.

\section{Statins induce ferroptosis}

The term ferroptosis, which was coined in 2012 [248], is a form of programmed cell death (PCD) that differs from apoptosis, necrosis, pyroptosis and autophagy [249, 250]. Ferroptosis is associated with the occurrence of multiple diseases [251,252] and its role in the treatment of cancer has attracted increasing attention [253-258]. In essence, ferroptosis is a process that occurs as a result of metabolic dysregulation, and is characterized by iron overload, lipid reactive oxygen species (ROS) accumulation, and lipid peroxidation [248]. Ferroptosis is inhibited by sequestration of free iron, inhibition of polyunsaturated fatty acid (PUFA) synthesis, or scavenging of ROS. Ferroptosis and lipid peroxidation are mainly controlled by three parallel systems: the glutathione (GSH)/glutathione peroxidase 4 (GPX4) axis, the ferroptosis suppressor protein 1 (FSP1)/ubiquinone (CoQ10)/NAD(P) $\mathrm{H}$ axis and the GTP cyclohydrolase 1 (GCH1)/tetrahydrobiopterin (BH4)/phospholipid axis [259-261]. The induction of ferroptosis in tumor cells is a promising anti-tumor strategy. 
Statins are associated with ferroptosis via the mevalonate pathway (Fig. 4), which is closely related to the regulation of the GSH/GPX4 and FSP1/CoQ10/NAD(P) $\mathrm{H}$ axes. The mevalonate pathway is crucial for the synthesis of GPX4 itself and generation of the CoQ10 backbone. IPP produced by the mevalonate pathway is the precursor of CoQ10.IPP positively regulates Sec-tRNA, which functions as a key regulatory element during the maturation of GPX4 [262, 263]. Blocking the rate-limiting enzyme in the mevalonate pathway by using statins compromises the efficient translation of GPX4 and consequently sensitizes cells to ferroptosis [264, 265]. It was recently revealed that the mechanism underlying the protective effect of CoQ10 is based on the ability of FSP1 to use CoQ10 as a substrate to hinder lipid autoxidation $[259,260]$. A recent study showed that drug-resistant cancer cells in a high-mesenchymal cell state were sensitive to ferroptosis induced by GPX4 inhibition or statin treatment. Fluvastatin treatment decreased GPX4 expression in a time- and concentration-dependent manner and its effects are enhanced by combination with the direct GPX4 inhibitor RSL3 [264]. Therefore, in the absence of bioavailable GPX4 inhibitors, statins stand out as candidates for the therapeutic induction of ferroptosis in highly mesenchymal and chemotherapy-resistant cancer cells.

\section{Statins induce pyroptosis}

Pyroptosis is an inflammatory form of PCD that is distinct from autophagy and ferroptosis. It was first described in myeloid cells infected by pathogens or bacteria in 1992 [266-268]. Pyroptosis is characterized by cell swelling, rupture, lysis and release of pro-inflammatory molecules, such as IL-1 $\beta$ and IL-18 $[269,270]$ and is induced by members of the gasdermin superfamily, including GSDMA, GSDMB, GSDMC, GSDMD, and GSDME [271-276]. The inflammasome activates caspase family proteins to cleave gasdermin. The resulting active form of the protein translocates to the cell membrane, forming pores that lead to cell swelling, cytoplasmic outflow, cell membrane rupture and eventually cell pyroptosis [273-275]. Generally, GSDMD, which is downstream of inflammasome activation, is cleaved by inflammatory caspases (caspase1/4/5/11) to induce pyroptosis, while GSDME is cleaved by apoptotic caspases (caspase 3) to induce pyroptosis [272]. There are two main pathways of pyroptosis: the caspase-1-mediated canonical pathway and the caspase-4/5/11-mediated non-canonical pathway. In the canonical pathway, danger is sensed through inflammasomes, leading to the recruitment and activation of caspase-1, which activates inflammatory factors such as IL- 18 and IL- $1 \beta$ and cleaves the N-terminal sequence of GSDMD. The activated form of GSDMD then bind to the cell membrane to generate pores and induce pyroptosis [277]. In the non-canonical pathway, human homologs caspase-4, 5 and murine caspase-11 recognize and bind to the bacterial lipopolysaccharide (LPS) and then cleave GSDMD, leading indirectly to caspase- 1 activation and pyroptosis [271, 274].

Many studies have shown that pyroptosis is closely related to the occurrence and development of various diseases, such as cancer [267, 278, 279]. For example, recent studies have shown that the low GSDMD expression significantly promotes the proliferation of gastric cancer cell both in vivo and in vitro [280]. Zhou et al. demonstrated that that iron supplementation at appropriate doses in iron-deficient patients is sufficient to maximize the anti-tumor effects of clinical ROS-inducing drugs, and inhibit the growth and metastasis of melanoma cells through GSDME-dependent pyroptosis [281]. A recent study showed that atorvastatin inhibits pyroptosis through the long non-coding RNA (lncRNA) NEXNAS1/NEXN pathway in human vascular endothelial cells [282]. In a mouse model of cardiac injury induced by coronary microembolization, rosuvastatin decreased the expression of NLRP3, caspase-1, interleukin-1 $\beta$ and GSDMD N-terminal domains, suggesting that this drug can protect against this type of cardiac injury by inhibiting pyroptosis [283]. However, the potential role of pyroptosis in the anti-tumor effects of statins remains to be fully elucidated.

\section{Statins target the TME}

Tumor microenvironment (TME) denotes the non-cancerous cells and components presented in the tumor, including molecules produced and released by them (Fig. 5). Over time, cancer has been recognized as an evolutionary and ecological process that involves constant, dynamic, and reciprocal interactions between cancer cells and TME [284]. The constant interaction between tumor cells and the TME plays a decisive role in tumor initiation, progression, metastasis, and response to therapy. The acquisition and maintenance of the hallmarks of cancer, such as maintained proliferation signaling, resistance to cell death, angiogenesis, activation of invasion and metastasis, and the induction of tumor-promoting inflammation, as well as the evasion of immune destruction, depend to varying degrees on the contribution of TME.

Given our increased understanding of the crucial roles of the TME in tumor development and therapeutic resistance, the focus of cancer research and treatment has gradually switched from a cancer-centric model to a TME-centric model. Efforts have been made to target components of the TME to achieve therapeutic benefits for cancer patients. We have introduced some specialized 


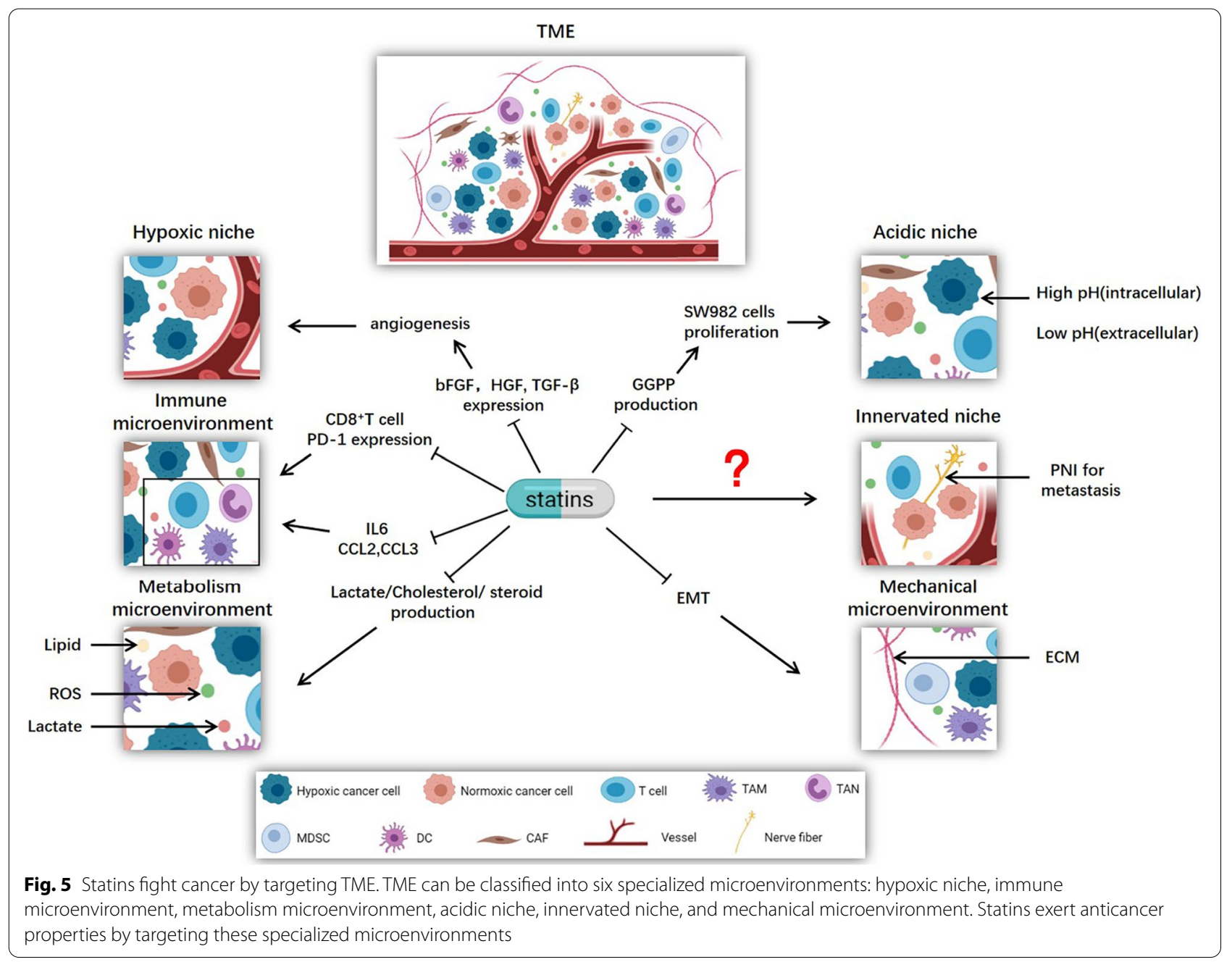

microenvironments in TME, focusing on hypoxic niche, immune microenvironment, metabolism microenvironment, acidic niche, innervated niche, and mechanical microenvironment (Fig. 5) [285]. Compared with the whole TME, a specialized microenvironment seems to be a better target for cancer treatment. The anti-tumor effects of some conventional drugs have been shown to be mediated by targeting the TME. Statins have been observed to exert anti-tumor effects by targeting these specialized microenvironments.

In the metabolic microenvironment, simvastatin has been shown to induce metabolic reprogramming in a mouse model of head and neck squamous cell carcinoma (HNSCC) by reducing the production of lactic acid and cancer sensitivity to monocarboxylate transporter 1 (MCT1) inhibitor, thereby inhibiting HNSCC [125].

In the mechanical microenvironment, simvastatin repolarizes tumor-associated macrophages (TAM) and promotes M2-to-M1 phenotype switching of macrophages via cholesterol-associated LXR/ABCA1 regulation, thereby remodeling the tumor microenvironment and inhibiting EMT [286].

Statins are also reported to target the immune microenvironment through cytokines or chemokines and immune checkpoints. Statins inhibit the survival of lung cancer cells by inhibiting the secretion of CCL3 by lung cancer cells as well as IL- 6 and CCL2 secretion by mesenchymal stromal cells, indicating the potential of statins as repurposed drugs for targeting the immune TME [108]. In inflammatory breast cancer (IBC), simvastatin blocks the activation of mesenchymal stem cells by decreasing IL-6 production [287]. A recent study showed that simvastatin can enhance the anti-tumor activity of $\mathrm{CD} 8^{+} \mathrm{T}$ cells by reducing cholesterol in the TME [116].

Hypoxia is induced in tumors by the outgrowth of cancer cells and unmatched angiogenesis and oxygen supply, accompanied by changes in the rate of cancer cell metabolism. Hypoxia activates vascular endothelial cells, upregulates vascular endothelial growth factor (VEGF) transcription, and stimulates excessive 
angiogenesis, thereby influencing the TME and therapeutic effects [288-291]. Statins have been shown to inhibit GGPP biosynthesis, and signal transduction via the Ras/ERK and Ras/Akt pathways, thereby suppressing the expression of basic fibroblast growth factor (bFGF), hepatocyte growth factor (HGF) and transforming growth factor- $\beta$ (TGF- $\beta$ ) in LM8 cells. These results suggest that statins are potentially useful as anti-angiogenic agents for the treatment of osteosarcoma [121].

In the acidic niche, statins inhibited the proliferation of the human synovial sarcoma cell line SW982 by reducing the production of GGPP [292]. Many studies have shown that statins can influence and regulate the central and the peripheral nervous systems [293-295]. However, there is no conclusive evidence to show that statins exert anti-cancer effects by targeting the innervated niche, and further studies are required to clarify this issue.

Thus, a large amount of evidence shows that statins can exert anti-tumor properties by targeting TME, and repurposing statins to target the TME has shown considerable advantages. These findings indicate that statins can target multiple microenvironments and highlight the great potential for their use in combination with approaches such as immunotherapy, chemotherapy, and targeted therapy.

\section{Maximizing efficacy and addressing shortcomings of conventional cancer therapy}

In recent years, many clinical and preclinical studies have shown the potential of statins to improve the efficacy of various cancer treatments when delivered before or in combination with other therapeutic interventions. Consequently, statins are increasingly considered as potential adjuvant agents in the treatment of cancer. In this regard, statins have unique advantages in that they are safe, well-tolerated and inexpensive, indicating that repurposing these agents may yield a cost-effective, lowtoxicity adjuvant therapy for cancer patients. However, in the era of precision medicine, further investigation into drug combination strategies will remain an important area of research [296]. Here, we discuss not only the effects of various statins combination strategies for cancer therapy, but also their unique benefits in terms of addressing the shortcomings of conventional cancer therapy.

In preclinical studies, statins have shown great promise in combined therapies and may act synergistically with some types of widely used forms of chemotherapy. For example, using in vitro and in vivo metabolism tracking, McGregor et al. recently showed that pancreatic ductal adenocarcinoma (PDAC) tumors rely on CoQ synthesized by the mevalonate pathway, and that statins induce cellular oxidative stress via this pathway.
Furthermore, simvastatin combined with mitogen-activated protein kinase (MEK) inhibitors was found to significantly enhance pancreatic tumor apoptosis in mice [297]. Taccioli et al. identified that dasatinib and statins are an effective combined strategy for inhibiting YAP/ TAZ in cancer cells by interrogating the Mutations and Drugs Portal (MDP) [298]. Iannelli et al. demonstrated the ability of the valproic acid/simvastatin combination to sensitize metastatic castration-resistant prostate cancer cells to docetaxel and to revert docetaxel-resistance through mevalonate pathway/YAP axis modulation using both in vitro and in vivo models [299]. Adriamycin-based chemotherapy is the first-line treatment for osteosarcoma, but most patients will experience tumor recurrence and metastasis. Adriamycin treatment has been shown to induce a stem-like phenotype and promote metastatic potential in osteosarcoma cells by upregulating the Yamanaka factor KLF4. In addition, statins significantly reversed adriamycin-induced cancer stem cell properties and metastasis by downregulating KLF4. Simvastatin also significantly inhibited adriamycin-enhanced tumorigenesis of KHOS/NP cells in vivo. These data indicate that the combined use of statins should be considered for selective inhibition of KLF4 in the development of osteosarcoma therapeutics [300]. Similarly, as the main therapeutic strategy for colorectal cancer, 5-FU-based treatment options have some shortcomings, including the risk of chemotherapy resistance. Recent evidence suggests that simvastatin may enhance the sensitivity of C26 mouse colon cancer cells to 5-FU treatment [301]. Pereira et al. found that statins temporarily modulated the epidermal growth factor receptor (EGFR) and prostate specific membrane antigen (PSMA) on the surface of tumor cells, which enhanced the tumor-binding avidity of the monoclonal antibodies panitumumab, cetuximab and huJ591, thereby synergizing with the antitumor effects of these agents [302]. It has also been reported that lovastatin enhanced the sensitivity of gallbladder cancer to cisplatin [303].

Similarly, in clinical studies, statins have been shown to be effective in adjuvant cancer treatment. Recent clinical studies have shown that high-intensity statins are associated with improved clinical activity of PD-1 inhibitors, and the combined application can improve the prognosis of patients with malignant pleural mesothelioma and advanced non-small cell lung cancer [69]. A recent cohort study from Taiwan has shown that statins are associated with increased survival in lung cancer patients treated with epidermal growth factor receptor-tyrosine kinase inhibitors (EGFR-TKIs) and exert synergistic anti-cancer effects [304]. Similarly, another cohort study of 1,835 patients with gastric cancer from Taiwan, suggested that the statin use improves the overall survival 
of patients with gastric cancer after surgery and adjuvant chemotherapy [60]. A recent multicenter observational retrospective study showed that the use of statins was independently associated with an increased objective response rate (ORR) of cancer patients treated with PD-1/PD-L1 inhibitors [305]. Interestingly, both metformin and statins significantly reduced prostate cancer tumor invasiveness, and this effect was enhanced (in vitro and vivo) when used in combination [306]. Recently, Longo et al. also found that phosphodiesterase (PDE) inhibitors can enhance statin-induced apoptosis, which may pave the way for the combination of PDE inhibitors and statins in the treatment of hematological malignancies [307].Therefore, a large body of preclinical and clinical evidence shows that statins play a synergistic anti-tumor role when administered in combination with conventional cancer therapy. This evidence may provide references for the inclusion of statins in the future cancer therapy.

Interestingly, statins can not only maximize the efficacy of conventional cancer therapy, but also address the shortcomings of conventional cancer therapy. Although great progress has been made in the field of cancer therapy, chemotherapy and radiotherapy remain the mainstay of cancer therapeutic modalities are extensively used in combination with surgery. While radiotherapy and chemotherapy can improve the survival of cancer patients, these treatments are also associated with serious shortcomings that influence the quality of life of cancer patients. Despite great efforts in the development of new cancer treatment strategies, limited attention has been paid to addressing the shortcomings of cancer treatment. Therefore, in addition to improving survival rates, clinical interventions are urgently needed to minimize the shortcomings and side-effects induced by radiotherapy and chemotherapy and improve the quality of life of cancer patients. In recent years, statins have attracted widespread attention due not only to their anti-tumor properties, but also their potential to address the shortcomings and side-effects of radiotherapy and chemotherapy.

Cisplatin is one of the most widely used anticancer drugs in the treatment of a variety of malignant tumors. It is also the most ototoxic drug in clinical use, causing permanent hearing loss in approximately $50 \%$ of treated patients [308-312]. A recent study showed that atorvastatin significantly reduced the incidence and severity of cisplatin-induced hearing loss [313]. In a propensity score-matched cohort study, statin-exposed women had a lower risk of heart failure (HF)-related hospital presentations after anthracycline chemotherapy for early breast cancer, with non-significant trends toward lower risk following treatment with trastuzumab. These findings support the ability of statins to prevent the cardiotoxicity of chemotherapy [314]. In addition, a fraction of patients undergoing androgen deprivation therapy for advanced prostate cancer will develop recurrent castrate-resistant prostate cancer in bone. But recently, Pan et al. found that statins can reduce castration-induced bone marrow adiposity and prostate cancer progression in bone [315]. The safety and toxicity profiles of statins also represent advantages for their use as adjuvant therapy in addressing the shortcomings and side-effects of cancer treatments. Statins used alone and in combined regimens have shown unparalleled advantages as anti-cancer agents and addressing the shortcomings and side-effects of conventional cancer treatments. However, the molecular mechanisms by which statins address these shortcomings and side-effects require clarification to provide a basis for the rational combination of statins and anticancer drugs to optimize cancer therapy.

\section{Conclusions and future perspectives}

Statins belong to a class of lipid-lowering drugs that were originally developed to treat cardiovascular disease. In recent decades, statins have been found to have nonlipid-related effects and are widely recognized as pleiotropic drugs. The anti-tumor properties of statins have received the most attention and have been confirmed in numerous preclinical studies. Here, we have summarized the latest information relating to the anti-tumor mechanisms of statins. The mevalonate pathway was the first anti-tumor mechanism of statins to be discovered and is also the most comprehensively characterized. Statins modulate cell proliferation, differentiation, and apoptosis by depletion of mevalonate pathway intermediates, which interferes with the post-translational modification and activation of small GTPases and their downstream signaling. In addition, the mevalonate pathway is required for the de novo biosynthesis of cholesterol and several studies have shown that cellular cholesterol levels are significantly associated with cancer. Therefore, we have described the role of the mevalonate pathway in antitumor mechanism of statins from the perspectives of the cholesterol-mediated pathway and the non-cholesterolmediated pathways. Moreover, we have summarized the latest discoveries that further clarify the anti-tumor mechanisms of statins, including autophagy, ferroptosis, targeting the tumor microenvironment, and pyroptosis. The improved understanding of these mechanisms will help elucidate the anti-tumor properties of statins and guide clinical trials of statins, thus facilitating the identification of novel cancer therapies.

In recent years, a large number of clinical and epidemiological studies on statins have been conducted, yielding both positive and negative results. Therefore, 
more well-designed clinical trials are required to validate the anti-cancer effects of statins. However, the value of statins as therapeutic agents against cancer in humans remains an area of active research. Although the clinical evidence that supports the use of statins as a monotherapy for cancer is not convincing, several preclinical and clinical studies indicate that statins potentiate the effects of currently used cancer therapies when administered in combination. Furthermore, statins have been shown to address the shortcomings and sideeffects caused by anticancer agents. Nevertheless, difficulties in statin administration at high doses remain unsolved, so satins are currently unlikely to be prescribed as a monotherapy. Therefore, we advocate the use of statins as an adjuvant therapy for cancer, which may be a more promising strategy than statin monotherapy. In addition, the large number of preclinical studies that have provided evidence of the anti-cancer properties of statins, as well as their safety and lack of toxicity, indicate that statins are ready to be investigated in well-designed prospective clinical trials, with lipophilic statins likely leading the charge.

In conclusion, statins are a potential adjuvant to cancer therapy, and more well-designed clinical trials are required to translate this potential to benefit patients.

\footnotetext{
Abbreviations

ABC: ATP-binding cassette; ABCA1: ATP-binding cassette subfamily A member 1; ABCG1: ABC subfamily G member 1; ACAT1: Acyl-CoA:cholesteryl acyltransferase 1; AKT: Protein kinase B; AML: Acute myeloid leukemia; AMPK: AMPactivated protein kinase; ApoA-I: Apolipoprotein A-l; ATG: Autophagy-related gene; bFGF: Basic fibroblast growth factor; BH4: Tetrahydrobiopterin; Bim: BCl-2 interacting mediator of cell death; BMP: Bone morphogenetic protein; CEs: Cholesteryl esters; Cl: Confidence interval; CoQ10: Ubiquinone; CRC: Colorectal cancer; CSCs: Cancer stem cells; DDS: Disease-specific survival; DNMT: DNA methyltransferase; EAC: Esophageal adenocarcinoma; ECC: Epirubicin, cisplatin and capecitabine; ECM: Extracellular matrix; EGFR: Epidermal growth factor receptor; EGFR-TKIs: Epidermal growth factor receptor-tyrosine kinase inhibitors; EMT: Epithelial-to-mesenchymal transition; ER: Endoplasmic reticulum; ERK: Extracellular regulated protein kinases; FAC: Fluorouracil, adriamycin and cyclophosphamide; FDPS: Farnesyl diphosphate synthase; FPP: Farnesyl pyrophosphate; FSP1: Ferroptosis suppressor protein 1; FTase: Farnesyltransferase; GBC: Gallbladder cancer; GBM: Glioblastoma; GC: Gastric cancer; GCH1: GTP cyclohydrolase 1; GGPP: Geranylgeranyl pyrophosphate; GGPPS: Geranylgeranyl pyrophosphate synthase; GGTase: Geranyltransferases; GLI1: Glioma-associated oncogene homolog 1; GPCR: G protein-coupled receptor; GPX4: Glutathione peroxidase 4; GSH: Glutathione; GTPases: Guanosinetriphosphate hydrolase; HCC: Hepatocellular carcinoma; HDLs: High-density lipids proteins; HF: Heart failure; HGF: Hepatocyte growth factor; HMG-CoA: 3-Hydroxy-3-methyl-glutaryl-CoA; HMGCR: 3-Hydroxy-3-methyl-glutaryl-CoA reductase; HNSCC: Head and neck squamous cell carcinoma; HR: Hazard ratio; IBC: Inflammatory breast cancer; IL: Interleukin; IPP: Isopentenyl pyrophosphate; LC3II: Light chain 3-phosphatidylethanolamine conjugate; LDL: Low-density lipoprotein; LDLR: Low-density lipoprotein receptor; LDs: Lipid droplets; LKB1: Liver kinase B1; IncRNA: Long non-coding RNA; LPS: Lipopolysaccharide; LXRs: Liver X receptors; MA: Mevalonate; MCT1: Monocarboxylate transporter 1; MDP: Mutations and Drugs Portal; MEK: Mitogen-activated protein kinase; MEV: Mevalonate; MM: Multiple myeloma; mTORC1: Mechanistic target of rapamycin complex 1; NHL: Non-Hodgkin lymphoma; NLRP3: Nodlike receptor protein 3; NR: Not reported; NSCLC: Non-small cell lung cancer; ORR: Objective response rate; OS: Overall survival; PARP: Poly(ADP-ribose)
}

polymerase; PBR: Peripheral benzodiazepine receptor; PCa: Prostate cancer; PCD: Programmed cell death; PCSK9: Proprotein-convertase-subtilisin-kexin type-9; PDAC: Pancreatic ductal adenocarcinoma; PDE: Phosphodiesterase; PD-1: Programmed death receptor-1; PFS: Progression-free survival; PI3K: Phosphatidylinositol-3-kinase; PSMA: Prostate specific membrane antigen; PTEN: Phosphatase and tensin homolog; PTTG1: Pituitary tumor-transforming gene 1; PUFA: Polyunsaturated fatty acid; p38MAPK: P38 mitogen-activated protein kinase; RCC: Renal cell carcinoma; ROCK: Rho-associated protein kinase; ROS: Reactive oxygen species; RR: Relative risk; SCAPs: SREBP cleavage activating proteins; SHH: Sonic Hedgehog; SMO: Smoothened receptor; SRE: Sterol regulatory elements; SREBPs: Sterol regulatory element binding proteins; TAE: Transcatheter arterial embolization; TAM: Tumor-associated macrophages; TGF- $\beta$ : Transforming growth factor- $\beta$; TME: Tumor microenvironment; TMZ: Temozolomide; TRAIL: TNF-related apoptosis inducing ligand; VEGF: Vascular endothelial growth factor; YAP: Yes-associated protein; 5-FU: 5-Fluorouracil; $\triangle \psi m$ : Mitochondrial membrane potential.

\section{Acknowledgements}

We appreciate the guidance of Ming-Zhu Jin. We apologize to those colleagues whose important work could not be cited due to space constraints.

\section{Authors' contributions}

WJ collected the related papers and was a major contributor in writing the manuscript. JWH made figures and tables. XRH revised the article. XYH and WLJ initiated the study and revised the manuscript. All authors read and approved the final manuscript.

\section{Funding}

This work was supported by the Natural Science Foundation of Anhui Province (1908085MH282).

Availability of data and materials

Not applicable.

\section{Declarations}

Ethics approval and consent to participate

Not applicable.

\section{Consent for publication}

All authors consent to publication.

\section{Competing interests}

The authors declare that they have no competing interests.

\section{Author details}

${ }^{1}$ Department of General Surgery, The Affiliated Provincial Hospital of Anhui Medical University, Hefei 230001, P. R. China. ${ }^{2}$ Department of Finance, The First Affiliated Hospital of University of Science and Technology of China (Anhui Provincial Hospital), Hefei 230001, P. R. China. ${ }^{3}$ Institute of Cancer Neuroscience, Medical Frontier Innovation Research Center, The First Hospital of Lanzhou University, The First Clinical Medical College of Lanzhou University, Lanzhou 730000, P. R. China. ${ }^{4}$ Department of General Surgery, The First Affiliated Hospital of University of Science and Technology of China (Anhui Provincial Hospital), Hefei 230001, P. R. China.

Received: 12 April 2021 Accepted: 13 July 2021

Published online: 24 July 2021

\section{References}

1. Sung H, Ferlay J, Siegel RL, Laversanne M, Soerjomataram I, Jemal A, Bray F. Global cancer statistics 2020: GLOBOCAN estimates of incidence and mortality worldwide for 36 cancers in 185 countries. CA Cancer J Clin. 2021;71(3):209-49. PMID: 33538338

2. Morgan S, Grootendorst P, Lexchin J, Cunningham C, Greyson D. The cost of drug development: a systematic review. Health Policy. 2011;100(1):4-17. PMID: 21256615. 
3. Gupta SC, Sung B, Prasad S, Webb LJ, Aggarwal BB. Cancer drug discovery by repurposing: teaching new tricks to old dogs. Trends Pharmacol Sci. 2013;34(9):508-17. PMID: 23928289.

4. Mohammadzadeh N, Montecucco F, Carbone F, Xu S, Al-Rasadi K, Sahebkar A. Statins: Epidrugs with effects on endothelial health? Eur J Clin Invest. 2020;50(12):e13388. PMID: 32854143.

5. Kodach LL, Jacobs RJ, Voorneveld PW, Wildenberg ME, Verspaget HW, van Wezel T, Morreau H, Hommes DW, Peppelenbosch MP, van den Brink GR, et al. Statins augment the chemosensitivity of colorectal cancer cells inducing epigenetic reprogramming and reducing colorectal cancer cell 'stemness' via the bone morphogenetic protein pathway. Gut. 2011;60(11):1544-53. PMID: 21551187.

6. Piccolo S, Cordenonsi M, Dupont S. Molecular pathways: YAP and TAZ take center stage in organ growth and tumorigenesis. Clin Cancer Res. 2013;19(18):4925-30. PMID: 23797907.

7. Sorrentino G, Ruggeri N, Specchia V, Cordenonsi M, Mano M, Dupont S, Manfrin A, Ingallina E, Sommaggio R, Piazza S, et al. Metabolic control of YAP and TAZ by the mevalonate pathway. Nat Cell Biol. 2014;16(4):357-66. PMID: 24658687.

8. Howe K, Sanat F, Thumser AE, Coleman T, Plant N. The statin class of HMG-CoA reductase inhibitors demonstrate differential activation of the nuclear receptors PXR, CAR and FXR, as well as their downstream target genes. Xenobiotica. 2011;41(7):519-29. PMID: 21476904.

9. Dulak J, Józkowicz A. Anti-angiogenic and anti-inflammatory effects of statins: relevance to anti-cancer therapy. Curr Cancer Drug Targets. 2005;5(8):579-94. PMID: 16375664.

10. Hamelin BA, Turgeon J. Hydrophilicity/lipophilicity: relevance for the pharmacology and clinical effects of HMG-CoA reductase inhibitors. Trends Pharmacol Sci. 1998:19(1):26-37. PMID: 9509899.

11. Kato S, Smalley S, Sadarangani A, Chen-Lin K, Oliva B, Brañes J, Carvajal J, Gejman R, Owen G, Cuello M. Lipophilic but not hydrophilic statins selectively induce cell death in gynaecological cancers expressing high levels of HMGCoA reductase. J Cell Mol Med. 2010;14(5):1180-93. PMID: 19432822.

12. Menter DG, Ramsauer VP, Harirforoosh S, Chakraborty K, Yang P, Hsi L, Newman RA, Krishnan K. Differential effects of pravastatin and simvastatin on the growth of tumor cells from different organ sites. PLoS One. 2011;6(12):e28813. PMID: 22216116.

13. Kazi DS, Penko JM, Bibbins-Domingo K. Statins for primary prevention of cardiovascular disease: review of evidence and recommendations for clinical practice. Med Clin North Am. 2017;101(4):689-99. PMID: 28577620

14. Yang Z, Wang H, Edwards D, Ding C, Yan L, Brayne C, Mant J. Association of blood lipids, atherosclerosis and statin use with dementia and cognitive impairment after stroke: a systematic review and metaanalysis. Ageing Res Rev. 2020;57:100962. PMID: 31505259.

15. Chung JW, Cha J, Lee MJ, Yu IW, Park MS, Seo WK, Kim ST, Bang OY. Intensive statin treatment in acute ischaemic stroke patients with intracranial atherosclerosis: a high-resolution magnetic resonance imaging study (STAMINA-MRI study). J Neurol Neurosurg Psychiatry. 2020;91(2):204-11. PMID: 31371644

16. Zhang Q, Dong J, Yu Z. Pleiotropic use of statins as non-lipid-lowering drugs. Int J Biol Sci. 2020;16(14):2704-11. PMID: 33110390.

17. Matusewicz L, Meissner J, Toporkiewicz M, Sikorski AF. The effect of statins on cancer cells-review. Tumour Biol. 2015;36(7):4889-904. PMID: 26002574.

18. Choi M, Han J, Yang B, Jang M, Kim M, Lee D, Kim T, Im S, Lee H, Moon $\mathrm{H}$, et al. Association of insulin, metformin, and statin with mortality in breast cancer patients. Cancer Res Treat. 2021;53(1):65-76. PMID: 32972040.

19. Cardwell C, Hicks B, Hughes C, Murray L. Statin use after diagnosis of breast cancer and survival: a population-based cohort study. Epidemiology. 2015;26(1):68-78. PMID: 25304447.

20. Ahern T, Pedersen L, Tarp M, Cronin-Fenton D, Garne J, Silliman R, Sørensen H, Lash T. Statin prescriptions and breast cancer recurrence risk: a Danish nationwide prospective cohort study. J Natl Cancer Inst. 2011;103(19):1461-8. PMID: 21813413.

21. Kwan ML, Habel LA, Flick ED, Quesenberry CP, Caan B. Post-diagnosis statin use and breast cancer recurrence in a prospective cohort study of early stage breast cancer survivors. Breast Cancer Res Treat. 2008;109(3):573-9. PMID: 17674197.
22. Tan N, Klein EA, Li J, Moussa AS, Jones JS. Statin use and risk of prostate cancer in a population of men who underwent biopsy. J Urol. 2011;186(1):86-90. PMID: 21571344.

23. Allott EH, Ebot EM, Stopsack KH, Gonzalez-Feliciano AG, Markt SC, Wilson KM, Ahearn TU, Gerke TA, Downer MK, Rider JR, et al. Statin use is associated with lower risk of PTEN-null and lethal prostate cancer. Clin Cancer Res. 2020;26(5):1086-93. PMID: 31754047.

24. Jespersen C, Nørgaard M, Friis S, Skriver C, Borre M. Statin use and risk of prostate cancer: a Danish population-based case-control study, 1997-2010. Cancer Epidemiol. 2014;38(1):42-7. PMID; 24275259

25. Coogan P, Kelly J, Strom B, Rosenberg L. Statin and NSAID use and prostate cancer risk. Pharmacoepidemiol Drug Saf. 2010;19(7):752-5. PMID: 20582910.

26. Chang $\mathrm{C}, \mathrm{Ho}, \mathrm{S}$, Chiu H, Yang C. Statins increase the risk of prostate cancer: a population-based case-control study. Prostate. 2011;71(16):181824. PMID: 21480313.

27. Abdel-Rahman O. Statin treatment and outcomes of metastatic pancreatic cancer: a pooled analysis of two phase III studies. Clin Transl Oncol. 2019;21(6):810-6. PMID: 30465184.

28. Huang B, Chang J, Li E, Xiang A, Wu B. Influence of statins and cholesterol on mortality among patients with pancreatic cancer. J Natl Cancer Inst. 2017;109(5):djw275. PMID: 28040693.

29. Yang P, Tsai Y, Chen K, Yang Y, Shih W. Statin use improves overall survival of patients with gastric cancer after surgery and adjuvant chemotherapy in Taiwan: a nationwide matched cohort study. Cancers. 2020;12(8):2055. PMID: 32722425.

30. Cho M, Yoo T, Jeong S, Shin DW. Association of aspirin, metformin, and statin use with gastric cancer incidence and mortality: a nationwide cohort study. Cancer Prev Res (Phila). 2021;14(1):95-104. PMID: 32938643.

31. Voorneveld PW, Reimers MS, Bastiaannet E, Jacobs RJ, van Eijk R, Zanders MMJ, Herings RMC, van Herk-Sukel MPP, Kodach LL, van Wezel $\mathrm{T}$, et al. Statin use after diagnosis of colon cancer and patient survival. Gastroenterology. 2017;153(2):470-479.e474. PMID: 28512021.

32. Li L, Cui N, Hao T, Zou J, Jiao W, Yi K, Yu W. Statins use and the prognosis of colorectal cancer: a meta-analysis. Clin Res Hepatol Gastroenterol. 2021;45(5):101588. PMID: 33662632

33. Verdoodt F, Kjaer Hansen M, Kjaer SK, Pottegård A, Friis S, Dehlendorff C. Statin use and mortality among ovarian cancer patients: a population-based cohort study. Int J Cancer. 2017;141(2):279-86. PMID: 28411390

34. Couttenier A, Lacroix O, Vaes E, Cardwell CR, De Schutter H, Robert A. Statin use is associated with improved survival in ovarian cancer: a retrospective population-based study. PLoS One. 2017;12(12):e0189233. PMID: 29261726.

35. Hung M, Chen I, Lee C, Huang R, Chen P, Tsai Y, Yang Y. Statin improves survival in patients with EGFR-TKI lung cancer: a nationwide population-based study. PLoS One. 2017;12(2):e0171137. PMID: 28158206.

36. Cardwell C, MC Menamin Ú, Hughes C, Murray L. Statin use and survival from lung cancer: a population-based cohort study. Cancer Epidemiol Biomarkers Prev. 2015;24(5):833-41. PMID: 25934831.

37. Ung MH, MacKenzie TA, Onega TL, Amos Cl, Cheng C. Statins associate with improved mortality among patients with certain histological subtypes of lung cancer. Lung Cancer. 2018;126:89-96. PMID: 30527197.

38. Cho S, Yang Y, Liu Y, Hsiao H, Huang C, Wu C, Tsai Y, Wang H, Liu T. Previous exposure to statin may reduce the risk of subsequent non-hodgkin lymphoma: a nationwide population-based case-control study. PLoS One. 2015;10(10):e0139289. PMID: 26425850.

39. Smyth L, Blunt DN, Gatov E, Nagamuthu C, Croxford R, Mozessohn L, Cheung MC. Statin and cyclooxygenase-2 inhibitors improve survival in newly diagnosed diffuse large B-cell lymphoma: a large populationbased study of 4913 subjects. Br J Haematol. 2020;191(3):396-404. PMID: 32304100

40. Seliger C, Schaertl J, Gerken M, Luber C, Proescholdt M, Riemenschneider MJ, Leitzmann MF, Hau P, Klinkhammer-Schalke M. Use of statins or NSAIDs and survival of patients with high-grade glioma. PLoS One. 2018;13(12):e0207858. PMID: 30507932.

41. Seliger C, Meier C, Becker C, Jick S, Bogdahn U, Hau P, Leitzmann M. Statin use and risk of glioma: population-based case-control analysis. Eur J Epidemiol. 2016;31(9):947-52. PMID: 27041698. 
42. Cote D, Rosner B, Smith-Warner S, Egan K, Stampfer M. Statin use, hyperlipidemia, and risk of glioma. Eur J Epidemiol. 2019;34(11):9971011. PMID: 31559554.

43. Sperling C, Verdoodt F, Friis S, Dehlendorff C, Kjaer S. Statin use and risk of endometrial cancer: a nationwide registry-based case-control study. Acta Obstet Gynecol Scand. 2017;96(2):144-9. PMID: 27891577.

44. Nayan M, Punjani N, Juurlink D, Finelli A, Austin P, Kulkarni G, UlerykE, Hamilton R. Statin use and kidney cancer survival outcomes: a systematic review and meta-analysis. Cancer Treat Rev. 2017;52:105-16. PMID: 27992843.

45. Sanfilippo K, Keller J, Gage B, Luo S, Wang T, Moskowitz G, Gumbel J, Blue B, O'Brian K, Carson K. Statins are associated with reduced mortality in multiple myeloma. J Clin Oncol. 2016;34(33):4008-14. PMID: 27646948.

46. Lebo N, Griffiths R, Hall S, Dimitroulakos J, Johnson-Obaseki S. Effect of statin use on oncologic outcomes in head and neck squamous cell carcinoma. Head Neck. 2018;40(8):1697-706. PMID: 29934959.

47. Garwood ER, Kumar AS, Baehner FL, Moore DH, Au A, Hylton N, Flowers Cl, Garber J, Lesnikoski BA, Hwang ES, et al. Fluvastatin reduces proliferation and increases apoptosis in women with high grade breast cancer. Breast Cancer Res Treat. 2010;119(1):137-44. PMID: 19728082.

48. Feldt M, Bjarnadottir O, Kimbung S, Jirström K, Bendahl PO, Veerla S, Grabau D, Hedenfalk I, Borgquist S. Statin-induced anti-proliferative effects via cyclin D1 and p27 in a window-of-opportunity breast cancer trial. J Transl Med. 2015;13:133. PMID: 25925673.

49. Yulian ED, Siregar NC, Bajuadji. Combination of Simvastatin and FAC improves response to neoadjuvant chemotherapy in advanced local breast cancer. Cancer Res Treat. 2021. https://doi.org/10.4143/crt.2020. 1024. PMID: 33705623.

50. Longo J, Hamilton RJ, Masoomian M, Khurram N, Branchard E, Mullen PJ, Elbaz M, Hersey K, Chadwick D, Ghai S, et al. A pilot window-ofopportunity study of preoperative fluvastatin in localized prostate cancer. Prostate Cancer Prostatic Dis. 2020;23(4):630-7. PMID: 32203069.

51. Kim ST, Kang JH, Lee J, Park SH, Park JO, Park YS, Lim HY, Hwang IG, Lee SC, Park KW, et al. Simvastatin plus capecitabine-cisplatin versus placebo plus capecitabine-cisplatin in patients with previously untreated advanced gastric cancer: a double-blind randomised phase 3 study. Eur J Cancer. 2014:50(16):2822-30. PMID: 25218337.

52. Konings IR, van der Gaast A, van der Wijk LJ, de Jongh FE, Eskens FA, Sleijfer S. The addition of pravastatin to chemotherapy in advanced gastric carcinoma: a randomised phase II trial. Eur J Cancer. 2010;46(18):3200-4. PMID: 20727735.

53. Han JY, Lee SH, Yoo NJ, Hyung LS, Moon YJ, Yun T, Kim HT, Lee JS. A randomized phase II study of gefitinib plus simvastatin versus gefitinib alone in previously treated patients with advanced non-small cell lung cancer. Clin Cancer Res. 2011;17(6):1553-60. PMID: 21411446.

54. Jouve JL, Lecomte T, Bouché O, Barbier E, Khemissa Akouz F, Riachi G, Nguyen Khac E, Ollivier-Hourmand I, Debette-Gratien M, Faroux R, et al. Pravastatin combination with sorafenib does not improve survival in advanced hepatocellular carcinoma. J Hepatol. 2019;71(3):516-22. PMID: 31125576.

55. Kawata S, Yamasaki E, Nagase T, Inui Y, Ito N, Matsuda Y, Inada M, Tamura S, Noda S, Imai Y, et al. Effect of pravastatin on survival in patients with advanced hepatocellular carcinoma. A randomized controlled trial. Br J Cancer. 2001;84(7):886-91. PMID: 11286466.

56. Nielsen S, Nordestgaard B, Bojesen S. Statin use and reduced cancer-related mortality. N Engl J Med. 2012;367(19):1792-802. PMID: 23134381.

57. Wang A, Aragaki AK, Tang JY, Kurian AW, Manson JE, Chlebowski RT, Simon M, Desai P, Wassertheil-Smoller S, Liu S, et al. Statin use and allcancer survival: prospective results from the Women's Health Initiative. Br J Cancer. 2016;115(1):129-35. PMID: 27280630.

58. Mei Z, Liang M, Li L, Zhang Y, Wang Q, Yang W. Effects of statins on cancer mortality and progression: a systematic review and metaanalysis of 95 cohorts including 1,111,407 individuals. Int J Cancer. 2017;140(5):1068-81. PMID: 27859151.

59. Majidi A, Na R, Jordan SJ, De Fazio A, Webb PM. Statin use and survival following a diagnosis of ovarian cancer: a prospective observational study. Int J Cancer. 2021;148(7):1608-15. PMID: 33034053.
60. Yang PR, Tsai YY, Chen KJ, Yang YH, Shih WT. Statin use improves overall survival of patients with gastric cancer after surgery and adjuvant chemotherapy in Taiwan: a nationwide matched cohort study. Cancers (Basel). 2020;12(8):2055. PMID: 32722425.

61. Rosch PJ, McCully K. Statin use and reduced cancer-related mortality. N Engl J Med. 2013;368(6):576. PMID: 23388016.

62. Tamburrino D, Crippa S, Partelli S, Archibugi L, Arcidiacono PG, Falconi M, Capurso G. Statin use improves survival in patients with pancreatic ductal adenocarcinoma: a meta-analysis. Dig Liver Dis. 2020;52(4):3929. PMID: 32113888.

63. larrobino NA, Gill B, Bernard ME, Mishra MV, Champ CE. Targeting tumor metabolism with statins during treatment for advanced-stage pancreatic cancer. Am J Clin Oncol. 2018:41(11):1125-31. PMID: 29509593.

64. Liu B, Yi Z, Guan X, Zeng YX, Ma F. The relationship between statins and breast cancer prognosis varies by statin type and exposure time: a meta-analysis. Breast Cancer Res Treat. 2017;164(1):1-11. PMID: 28432513.

65. Bonovas S, Filioussi K, Tsavaris N, Sitaras NM. Use of statins and breast cancer: a meta-analysis of seven randomized clinical trials and nine observational studies. J Clin Oncol. 2005;23(34):8606-12. PMID: 16260694.

66. Geybels MS, Wright JL, Holt SK, Kolb S, Feng Z, Stanford JL. Statin use in relation to prostate cancer outcomes in a population-based patient cohort study. Prostate. 2013;73(11):1214-22. PMID: 23633265.

67. Agalliu I, Salinas CA, Hansten PD, Ostrander EA, Stanford JL. Statin use and risk of prostate cancer: results from a population-based epidemiologic study. Am J Epidemiol. 2008;168(3):250-60. PMID: 18556686.

68. Islam MM, Poly TN, Walther BA, Yang HC, Jack Li YC. Statin use and the risk of hepatocellular carcinoma: a meta-analysis of observational studies. Cancers (Basel). 2020;12(3):671. PMID: 32183029.

69. Cantini L, Pecci F, Hurkmans DP, Belderbos RA, Lanese A, Copparoni C, Aerts S, Cornelissen R, Dumoulin DW, Fiordoliva I, et al. High-intensity statins are associated with improved clinical activity of PD-1 inhibitors in malignant pleural mesothelioma and advanced non-small cell lung cancer patients. Eur J Cancer. 2021;144:41-8. PMID: 33326868.

70. Awan Z, Fahmy U, Badr-Eldin S, Ibrahim T, Asfour H, Al-Rabia M, Alfarsi A, Alhakamy N, Abdulaal W, Al Sadoun H, et al. The enhanced cytotoxic and pro-apoptotic effects of optimized simvastatinloaded emulsomes on MCF-7 breast cancer cells. Pharmaceutics. 2020;12(7):597. PMID: 32604984.

71. Wang T, Seah S, Loh X, Chan C, Hartman M, Goh B, Lee S. Simvastatininduced breast cancer cell death and deactivation of PI3K/Akt and MAPK/ERK signalling are reversed by metabolic products of the mevaIonate pathway. Oncotarget. 2016;7(3):2532-44. PMID: 26565813.

72. Alarcon Martinez T, Zeybek N, Müftüoğlu S. Evaluation of the cytotoxic and autophagic effects of atorvastatin on MCF-7 breast cancer cells. Balkan Med J. 2018;35(3):256-62. PMID: 29485098.

73. Koyuturk M, Ersoz M, Altiok N. Simvastatin induces apoptosis in human breast cancer cells: p53 and estrogen receptor independent pathway requiring signalling through JNK. Cancer Lett. 2007;250(2):220-8. PMID: 17125918.

74. Huang SW, Chyuan IT, Shiue C, Yu MC, Hsu YF, Hsu MJ. Lovastatinmediated MCF-7 cancer cell death involves LKB1-AMPK-p38MAPK-p53survivin signalling cascade. J Cell Mol Med. 2020;24(2):1822-36. PMID: 31821701.

75. Bai F, Yu Z, Gao X, Gong J, Fan L, Liu F. Simvastatin induces breast cancer cell death through oxidative stress up-regulating miR-140-5p. Aging. 2019;11(10):3198-219. PMID: 31138773.

76. Afzali M, Vatankhah M, Ostad S. Investigation of simvastatin-induced apoptosis and cell cycle arrest in cancer stem cells of MCF-7. J Cancer Res Ther. 2016;12(2):725-30. PMID: 27461641.

77. Lin Z, Zhang Z, Jiang X, Kou X, Bao Y, Liu H, Sun F, Ling S, Qin N, Jiang $L$, et al. Mevastatin blockade of autolysosome maturation stimulates LBH589-induced cell death in triple-negative breast cancer cells. Oncotarget. 2017;8(11):17833-48. PMID: 28147319.

78. Buranrat B, Suwannaloet W, Naowaboot J. Simvastatin potentiates doxorubicin activity against MCF-7 breast cancer cells. Oncol Lett. 2017;14(5):6243-50. PMID: 29113274.

79. Castellanos-Esparza YC, Wu S, Huang L, Buquet C, Shen R, SanchezGonzalez B, García Latorre EA, Boyer O, Varin R, Jiménez-Zamudio LA, 
et al. Synergistic promoting effects of pentoxifylline and simvastatin on the apoptosis of triple-negative MDA-MB-231 breast cancer cells. Int J Oncol. 2018;52(4):1246-54. PMID: 29436616.

80. Ghosh-Choudhury N, Mandal C, Ghosh-Choudhury N, Ghosh Choudhury G. Simvastatin induces derepression of PTEN expression via NFkappaB to inhibit breast cancer cell growth. Cell Signal. 2010;22(5):749-58. PMID: 20060890.

81. Herrero-Martin G, López-Rivas A. Statins activate a mitochondriaoperated pathway of apoptosis in breast tumor cells by a mechanism regulated by ErbB2 and dependent on the prenylation of proteins. FEBS Lett. 2008;582(17):2589-94. PMID: 18582466.

82. Deng J, Zhang R, Zeng Y, Zhu Y, Wang G. Statins induce cell apoptosis through a modulation of AKT/FOXO1 pathway in prostate cancer cells. Cancer Manag Res. 2019;11:7231-42. PMID: 31839714.

83. Alqudah M, Mansour H, Mhaidat N. Simvastatin enhances irinotecaninduced apoptosis in prostate cancer via inhibition of MCL-1. Saudi Pharm J. 2018;26(2):191-7. PMID: 30166915.

84. Chen B, Zhang M, Xing D, Feng Y. Atorvastatin enhances radiosensitivity in hypoxia-induced prostate cancer cells related with HIF-1a inhibition. Biosci Rep. 2017:37(4):BSR20170340. PMID: 28760843.

85. Wang Z, Zhang L, Wan Z, He Y, Huang H, Xiang H, Wu X, Zhang K, Liu $Y$, Goodin $S$, et al. Atorvastatin and caffeine in combination regulates apoptosis, migration, invasion and tumorspheres of prostate cancer cells. Pathol Oncol Res. 2020;26(1):209-16. PMID: 29796873.

86. Kochuparambil S, Al-Husein B, Goc A, Soliman S, Somanath P. Anticancer efficacy of simvastatin on prostate cancer cells and tumor xenografts is associated with inhibition of Akt and reduced prostate-specific antigen expression. J Pharmacol Exp Ther. 2011;336(2):496-505. PMID: 21059805.

87. Zheng X, Cui X, Gao Z, Zhao Y, Lin Y, Shih W, Huang M, Liu Y, Rabson A, Reddy $B$, et al. Atorvastatin and celecoxib in combination inhibits the progression of androgen-dependent LNCaP xenograft prostate tumors to androgen independence. Cancer Prev Res (Phila). 2010;3(1):114-24. PMID: 20051379.

88. Brown M, Hart C, Tawadros T, Ramani V, Sangar V, Lau M, Clarke N. The differential effects of statins on the metastatic behaviour of prostate cancer. Br J Cancer. 2012;106(10):1689-96. PMID: 22531631.

89. Toepfer N, Childress C, Parikh A, Rukstalis D, Yang W. Atorvastatin induces autophagy in prostate cancer PC3 cells through activation of LC3 transcription. Cancer Biol Ther. 2011;12(8):691-9. PMID: 21768780

90. Hoque A, Chen H, Xu XC. Statin induces apoptosis and cell growth arrest in prostate cancer cells. Cancer Epidemiol Biomarkers Prev. 2008;17(1):88-94. PMID: 18199714.

91. Chen Y, Chen Y, Lin C, Hsieh Y, Hsu C, Hsieh M. Synergistic anticancer effects of gemcitabine with pitavastatin on pancreatic cancer cell line MIA PaCa-2 in vitro and in vivo. Cancer Manag Res. 2020;12:4645-65. PMID: 32606957.

92. Ortiz N, Díaz C. Mevalonate pathway as a novel target for the treatment of metastatic gastric cancer. Oncol Lett. 2020;20(6):320. PMID: 33093924.

93. Liu Q, Xia H, Zhou S, Tang Q, Zhou J, Ren M, Bi F. Simvastatin inhibits the malignant behaviors of gastric cancer cells by simultaneously suppressing YAP and $\beta$-Catenin signaling. Onco Targets Ther. 2020;13:2057-66. PMID: 32210573.

94. Jang H, Hong E, Park S, Byun H, Koh D, Choi M, Kae S, Lee J. Statin induces apoptosis of human colon cancer cells and downregulation of insulin-like growth factor 1 receptor via proapoptotic ERK activation. Oncol Lett. 2016;12(1):250-6. PMID: 27347133.

95. Chang H, Chen C, Hsu Y, Kuo W, Ou G, Chiu P, Huang Y, Hsu M. Simvastatin induced HCT116 colorectal cancer cell apoptosis through p38MAPK-p53-survivin signaling cascade. Biochem Biophys Acta. 2013;1830(8):4053-64. PMID: 23583370.

96. Wu X, Song M, Qiu P, Rakariyatham K, Li F, Gao Z, Cai X, Wang M, Xu F, Zheng J, et al. Synergistic chemopreventive effects of nobiletin and atorvastatin on colon carcinogenesis. Carcinogenesis. 2017;38(4):45564. PMID: 28207072.

97. Sutter A, Maaser K, Höpfner M, Huether A, Schuppan D, Scherübl H. Cell cycle arrest and apoptosis induction in hepatocellular carcinoma cells by HMG-CoA reductase inhibitors. Synergistic antiproliferative action with ligands of the peripheral benzodiazepine receptor. J Hepatol. 2005:43(5):808-16. PMID: 16083991.
98. Wang S, Huang S, Liu K, Lee T, Shieh J, Wu C. Atorvastatin-induced senescence of hepatocellular carcinoma is mediated by downregulation of hTERT through the suppression of the IL-6/STAT3 pathway. Cell Death Discov. 2020;6:17. PMID: 32257389.

99. Docrat T, Nagiah S, Krishnan A, Naidoo D, Chuturgoon A. Atorvastatin induces MicroRNA-145 expression in HEPG2 cells via regulation of the PI3K/AKT signalling pathway. Chem Biol Interact. 2018;287:32-40. PMID: 29630879.

100. Wang S, Ho H, Lin J, Shieh J, Wu C. Simvastatin-induced cell cycle arrest through inhibition of STAT3/SKP2 axis and activation of AMPK to promote p27 and p21 accumulation in hepatocellular carcinoma cells. Cell Death Dis. 2017;8(2):e2626. PMID: 28230855.

101. You H, Zhang W, Xie X, Zheng Z, Zhu H, Jiang F. Pitavastatin suppressed liver cancer cells in vitro and in vivo. Onco Targets Ther. 2016;9:5383-8. PMID: 27621652.

102. Xia K, Zhang P, Hu J, Hou H, Xiong M, Xiong J, Yan N. Synergistic effect of receptor-interacting protein 140 and simvastatin on the inhibition of proliferation and survival of hepatocellular carcinoma cells. Oncol Lett. 2018;15(4):4344-50. PMID: 29541202.

103. Liu H, Liang S, Kumar S, Weyman C, Liu W, Zhou A. Statins induce apoptosis in ovarian cancer cells through activation of JNK and enhancement of Bim expression. Cancer Chemother Pharmacol. 2009;63(6):9971005. PMID: 18766339.

104. Kobayashi Y, Kashima H, Wu R, Jung J, Kuan J, Gu J, Xuan J, Sokoll L, Visvanathan K, Shih I, et al. Mevalonate pathway antagonist suppresses formation of serous tubal intraepithelial carcinoma and ovarian carcinoma in mouse models. Clin Cancer Res. 2015;21 (20):4652-62. PMID: 26109099.

105. Otahal A, Aydemir D, Tomasich E, Minichsdorfer C. Delineation of cell death mechanisms induced by synergistic effects of statins and erlotinib in non-small cell lung cancer cell (NSCLC) lines. Sci Rep. 2020;10(1):959. PMID: 31969600.

106. Khanzada U, Pardo O, Meier C, Downward J, Seckl M, Arcaro A. Potent inhibition of small-cell lung cancer cell growth by simvastatin reveals selective functions of Ras isoforms in growth factor signalling. Oncogene. 2006;25(6):877-87. PMID: 16170339.

107. Liu H, Wang Z, Li Y, Li W, Chen Y. Simvastatin prevents proliferation and bone metastases of lung adenocarcinoma in vitro and in vivo. Neoplasma. 2013;60(3):240-6. PMID: 23373992.

108. Galland S, Martin P, Fregni G, Letovanec I, Stamenkovic I. Attenuation of the pro-inflammatory signature of lung cancer-derived mesenchymal stromal cells by statins. Cancer Lett. 2020;484:50-64. PMID: 32418888.

109. Qi X, Zheng L, Lee K, Kim D, Kim C, Cai D, Wu Z, Qin J, Yu Y, Kim S. HMG-CoA reductase inhibitors induce apoptosis of lymphoma cells by promoting ROS generation and regulating Akt, Erk and p38 signals via suppression of mevalonate pathway. Cell Death Dis. 2013;4:e518. PMID: 23449454

110. Song $X$, Liu BC, Lu XY, Yang LL, Zhai YJ, Eaton AF, Thai TL, Eaton DC, Ma HP, Shen BZ. Lovastatin inhibits human B lymphoma cell proliferation by reducing intracellular ROS and TRPC 6 expression. Biochim Biophys Acta. 2014;1843(5):894-901. PMID: 24518247.

111. Sheikholeslami K, Ali Sher A, Lockman S, Kroft D, Ganjibakhsh M, NejatiKoshki K, Shojaei S, Ghavami S, Rastegar M. Simvastatin induces apoptosis in medulloblastoma brain tumor cells via mevalonate cascade prenylation substrates. Cancers. 2019;11(7):994. PMID: 31319483.

112. Shojaei S, Koleini N, Samiei E, Aghaei M, Cole LK, Alizadeh J, Islam MI, Vosoughi AR, Albokashy M, Butterfield Y, et al. Simvastatin increases temozolomide-induced cell death by targeting the fusion of autophagosomes and lysosomes. FEBS J. 2020;287(5):1005-34. PMID: 31545550.

113. Ivanov V, Hei T. Regulation of apoptosis in human melanoma and neuroblastoma cells by statins, sodium arsenite and TRAIL: a role of combined treatment versus monotherapy. Apoptosis. 2011;16(12):1268-84. PMID: 21910007.

114. Al-Qatati A, Aliwaini S. Combined pitavastatin and dacarbazine treatment activates apoptosis and autophagy resulting in synergistic cytotoxicity in melanoma cells. Oncol Lett. 2017;14(6):7993-9. PMID: 29344241.

115. Shellman Y, Ribble D, Miller L, Gendall J, Vanbuskirk K, Kelly D, Norris D, Dellavalle R. Lovastatin-induced apoptosis in human melanoma cell lines. Melanoma Res. 2005;15(2):83-9. PMID: 15846140. 
116. Ma X, Bi E, Lu Y, Su P, Huang C, Liu L, Wang Q, Yang M, Kalady MF, Qian J, et al. Cholesterol induces CD8(+) T cell exhaustion in the tumor microenvironment. Cell Metab. 2019;30(1):143-156.e145. PMID: 31031094.

117. Ogunwobi O, Beales I. Statins inhibit proliferation and induce apoptosis in Barrett's esophageal adenocarcinoma cells. Am J Gastroenterol. 2008;103(4):825-37. PMID: 18371146

118. Lee J, Hong E, Jang J, Park S, Koh D, Choi M, Jang H, Kae S. Simvastatin induces apoptosis and suppresses insulin-like growth factor 1 receptor in bile duct cancer cells. Gut Liver. 2016:10(2):310-7. PMID: 26470769.

119. Miller T, Yang F, Wise CE, Meng F, Priester S, Munshi MK, Guerrier M, Dostal DE, Glaser SS. Simvastatin stimulates apoptosis in cholangiocarcinoma by inhibition of Rac1 activity. Dig Liver Dis. 2011;43(5):395-403. PMID: 21334995.

120. Kamel W, Sugihara E, Nobusue H, Yamaguchi-Iwai S, Onishi N, Maki K, Fukuchi Y, Matsuo K, Muto A, Saya H, et al. Simvastatin-induced apoptosis in osteosarcoma cells: a key role of RhoA-AMPK/p38 MAPK signaling in antitumor activity. Mol Cancer Ther. 2017;16(1):182-92. PMID: 27799356.

121. Tsubaki M, Yamazoe $Y$, Yanae M, Satou T, Itoh T, Kaneko J, Kidera Y, Moriyama K, Nishida S. Blockade of the Ras/MEK/ERK and Ras/PI3K/Akt pathways by statins reduces the expression of bFGF, HGF, and TGF- $\beta$ as angiogenic factors in mouse osteosarcoma. Cytokine. 2011;54(1):100-7. PMID: 21292498.

122. Yen C, Chen J, Chang Y, Hsu Y, Chiu P, Shiue C, Chuang Y, Ou G, Hsu M. Lovastatin causes FaDu hypopharyngeal carcinoma cell death via AMPK-p63-survivin signaling cascade. Sci Rep. 2016;6:25082. PMID: 27122225.

123. Peng Y, He G, Tang D, Xiong L, Wen Y, Miao X, Hong Z, Yao H, Chen C, Yan S, et al. Lovastatin inhibits cancer stem cells and sensitizes to chemo- and photodynamic therapy in nasopharyngeal carcinoma. J Cancer. 2017:8(9):1655-64. PMID: 28775785.

124. Gehrke T, Scherzad A, Hackenberg S, Ickrath P, Schendzielorz P, Hagen $\mathrm{R}$, Kleinsasser N. Additive antitumor effects of celecoxib and simvastatin on head and neck squamous cell carcinoma in vitro. Int J Oncol. 2017:51(3):931-8. PMID: 28713941.

125. Mehibel M, Ortiz-Martinez F, Voelxen N, Boyers A, Chadwick A, Telfer BA, Mueller-Klieser W, West CM, Critchlow SE, Williams KJ, et al. Statin-induced metabolic reprogramming in head and neck cancer: a biomarker for targeting monocarboxylate transporters. Sci Rep. 2018:8(1):16804. PMID: 30429503.

126. Lee N, Tilija Pun N, Jang W, Bae J, Jeong C. Pitavastatin induces apoptosis in oral squamous cell carcinoma through activation of FOXO3a. $J$ Cell Mol Med. 2020;24(12):7055-66. PMID: 32406610.

127. Zhang L, Chen T, Dou Y, Zhang S, Liu H, Khishignyam T, Li X, Zuo D, Zhang Z, Jin M, et al. Atorvastatin exerts antileukemia activity via inhibiting mevalonate-YAP Axis in K562 and HL60 cells. Front Oncol. 2019;9:1032. PMID: 31649888

128. Jang J, Lee J, Jang J, Jung C, Park S. Anti-leukemic effects of simvastatin on NRAS mutant acute myeloid leukemia cells. Mol Biol Rep. 2019;46(6):5859-66. PMID: 31452046.

129. Kim S, Lee E, Lee J, Yang W, Nam D, Lee J, Lee S, Um J, Shim B, Ahn K. Simvastatin in combination with bergamottin potentiates TNF-induced apoptosis through modulation of NF-kB signalling pathway in human chronic myelogenous leukaemia. Pharm Biol. 2016;54(10):2050-60. PMID: 26911804.

130. Trojan P, Bohatch-Junior M, Otuki M, Souza-Fonseca-Guimarães F, Svidnicki P, Nogaroto V, Fernandes D, Krum E, Favero G. Pravastatin induces cell cycle arrest and decreased production of VEGF and bFGF in multiple myeloma cell line. Braz J Biol. 2016;76(1):59-65. PMID: 26909624.

131. Tu Y, Kang X, Zhou J, Lv X, Tang Y, Guan Y. Involvement of Chk1-Cdc25Acyclin A/CDK2 pathway in simvastatin induced S-phase cell cycle arrest and apoptosis in multiple myeloma cells. Eur J Pharmacol. 2011;670:356-64. PMID: 21958871.

132. Hagiwara N, Watanabe M, lizuka-Ohashi M, Yokota I, Toriyama S, Sukeno M, Tomosugi M, Sowa Y, Hongo F, Mikami K, et al. Mevalonate pathway blockage enhances the efficacy of mTOR inhibitors with the activation of retinoblastoma protein in renal cell carcinoma. Cancer Lett. 2018:431:182-9. PMID: 29778569.

133. Zhang Y, Liu Y, Duan J, Wang H, Zhang Y, Qiao K, Wang J. Cholesterol depletion sensitizes gallbladder cancer to cisplatin by impairing DNA damage response. Cell Cycle (Georgetown, Tex). 2019;18(23):3337-50. PMID: 31599189.

134. Kim J, Turbov J, Rosales R, Thaete L, Rodriguez G. Combination simvastatin and metformin synergistically inhibits endometrial cancer cell growth. Gynecol Oncol. 2019;154(2):432-40. PMID: 31178149.

135. Hanahan D, Weinberg RA. Hallmarks of cancer: the next generation. Cell. 2011;144(5):646-74. PMID: 21376230.

136. Goldstein JL, Brown MS. Regulation of the mevalonate pathway. Nature. 1990:343(6257):425-30. PMID: 1967820.

137. Göbel A, Rauner M, Hofbauer LC, Rachner TD. Cholesterol and beyond the role of the mevalonate pathway in cancer biology. Biochim Biophys Acta Rev Cancer. 2020;1873(2):188351. PMID: 32007596.

138. Juarez D, Fruman DA. Targeting the mevalonate pathway in cancer. Trends Cancer. 2021;7(6):525-40. PMID: 33358111.

139. Jeong A, Suazo KF, Wood WG, Distefano MD, Li L. Isoprenoids and protein prenylation: implications in the pathogenesis and therapeutic intervention of Alzheimer's disease. Crit Rev Biochem Mol Biol. 2018:53(3):279-310. PMID: 29718780.

140. Gruenbacher G, Thurnher M. Mevalonate metabolism in cancer. Cancer Lett. 2015:356(2 Pt A):192-6. PMID: 24467965.

141. Gruenbacher G, Thurnher M. Mevalonate metabolism in cancer stemness and trained immunity. Front Oncol. 2018;8:394. PMID: 30298120.

142. Mullen PJ, Yu R, Longo J, Archer MC, Penn LZ. The interplay between cell signalling and the mevalonate pathway in cancer. Nat Rev Cancer. 2016;16(11):718-31. PMID: 27562463.

143. Wang M, Casey PJ. Protein prenylation: unique fats make their mark on biology. Nat Rev Mol Cell Biol. 2016;17(2):110-22. PMID: 26790532.

144. Thurnher M, Nussbaumer O, Gruenbacher G. Novel aspects of mevalonate pathway inhibitors as antitumor agents. Clin Cancer Res. 2012;18(13):3524-31. PMID: 22529099.

145. Brown DN, Caffa I, Cirmena G, Piras D, Garuti A, Gallo M, Alberti S, Nencioni A, Ballestrero A, Zoppoli G. Squalene epoxidase is a bona fide oncogene by amplification with clinical relevance in breast cancer. Sci Rep. 2016;6:19435. PMID: 26777065.

146. Narwal V, Deswal R, Batra B, Kalra V, Hooda R, Sharma M, Rana JS. Cholesterol biosensors: a review. Steroids. 2019;143:6-17. PMID: 30543816

147. Cruz PM, Mo H, McConathy WJ, Sabnis N, Lacko AG. The role of cholesterol metabolism and cholesterol transport in carcinogenesis: a review of scientific findings, relevant to future cancer therapeutics. Front Pharmacol. 2013;4:119. PMID: 24093019.

148. Simons K, Ehehalt R. Cholesterol, lipid rafts, and disease. J Clin Invest. 2002;110(5):597-603. PMID: 12208858.

149. Thurnher M, Gruenbacher G, Nussbaumer O. Regulation of mevaIonate metabolism in cancer and immune cells. Biochim Biophys Acta. 2013;1831(6):1009-15. PMID: 23524243.

150. Konstantinopoulos PA, Karamouzis MV, Papavassiliou AG. Post-translational modifications and regulation of the RAS superfamily of GTPases as anticancer targets. Nat Rev Drug Discov. 2007;6(7):541-55. PMID: 17585331.

151. Cordle A, Koenigsknecht-Talboo J, Wilkinson B, Limpert A, Landreth G Mechanisms of statin-mediated inhibition of small G-protein function. J Biol Chem. 2005;280(40):34202-9. PMID: 16085653.

152. Schaafsma D, Roscioni SS, Meurs H, Schmidt M. Monomeric G-proteins as signal transducers in airway physiology and pathophysiology. Cell Signal. 2008;20(10):1705-14. PMID: 18538541.

153. Riganti C, Aldieri E, Doublier S, Bosia A, Ghigo D. Statins-mediated inhibition of rho GTPases as a potential tool in anti-tumor therapy. Mini Rev Med Chem. 2008;8(6):609-18. PMID: 18537716.

154. Casey PJ. Mechanisms of protein prenylation and role in $\mathrm{G}$ protein function. Biochem Soc Trans. 1995;23(1):161-6. PMID: 7758720.

155. Fritz G. HMG-CoA reductase inhibitors (statins) as anticancer drugs (review). Int J Oncol. 2005;27(5):1401-9. PMID: 16211237.

156. Der CJ, Cox AD. Isoprenoid modification and plasma membrane association: critical factors for ras oncogenicity. Cancer Cells. 1991;3(9):33140. PMID: 1751286.

157. Cox AD, Der CJ. Protein prenylation: more than just glue? Curr Opin Cell Biol. 1992:4(6):1008-16. PMID: 1485954.

158. Sheikholeslami K, Ali Sher A, Lockman S, Kroft D, Ganjibakhsh M, Nejati-Koshki K, Shojaei S, Ghavami S, Rastegar M. Simvastatin induces 
apoptosis in medulloblastoma brain tumor cells via mevalonate cascade prenylation substrates. Cancers (Basel). 2019;11(7):994. PMID: 31319483.

159. Zhu Y, Casey PJ, Kumar AP, Pervaiz S. Deciphering the signaling networks underlying simvastatin-induced apoptosis in human cancer cells: evidence for non-canonical activation of RhoA and Rac1 GTPases. Cell Death Dis. 2013;4(4):e568. PMID: 23559002.

160. Denoyelle C, Vasse M, Körner M, Mishal Z, Ganné F, Vannier JP, Soria J, Soria C. Cerivastatin, an inhibitor of HMG-CoA reductase, inhibits the signaling pathways involved in the invasiveness and metastatic properties of highly invasive breast cancer cell lines: an in vitro study. Carcinogenesis. 2001;22(8):1139-48. PMID: 11470741.

161. Kubatka P, Kruzliak P, RotrekIV, Jelinkova S, Mladosievicova B. Statins in oncological research: from experimental studies to clinical practice. Crit Rev Oncol Hematol. 2014;92(3):296-311. PMID: 25220658.

162. Li M, Min W, Wang J, Wang L, Li Y, Zhou N, Yang Z, Qian Q. Effects of mevalonate kinase interference on cell differentiation, apoptosis, prenylation and geranylgeranylation of human keratinocytes are attenuated by farnesyl pyrophosphate or geranylgeranyl pyrophosphate. Exp Ther Med. 2020;19(4):2861-70. PMID: 32256770.

163. Helbig $G$, Hołowiecki J. Ras signaling pathway as a target for farnesyltransferase inhibitors-a new, promising prospects in the treatment for malignant disorders. Wiad Lek. 2004;57(9-10):462-7. PMID: 15765763.

164. Hu T, Shen H, Huang H, Yang Z, Zhou Y, Zhao G. Cholesterollowering drug pitavastatin targets lung cancer and angiogenesis via suppressing prenylation-dependent Ras/Raf/MEK and PI3K/ Akt/mTOR signaling. Anticancer Drugs. 2020;31(4):377-84. PMID: 32011362.

165. Alizadeh J, Zeki AA, Mirzaei N, Tewary S, Rezaei Moghadam A, Glogowska A, Nagakannan P, Eftekharpour E, Wiechec E, Gordon JW, et al. Mevalonate cascade inhibition by simvastatin induces the intrinsic apoptosis pathway via depletion of isoprenoids in tumor cells. Sci Rep. 2017;7:44841. PMID: 28344327.

166. Cho SJ, Kim JS, Kim JM, Lee JY, Jung HC, Song IS. Simvastatin induces apoptosis in human colon cancer cells and in tumor xenografts, and attenuates colitis-associated colon cancer in mice. Int J Cancer. 2008;123(4):951-7. PMID: 18521906.

167. Fujiwara D, Tsubaki M, Takeda T, Tomonari Y, Koumoto YI, Sakaguchi K, Nishida S. Statins induce apoptosis through inhibition of Ras signaling pathways and enhancement of Bim and p27 expression in human hematopoietic tumor cells. Tumour Biol. 2017;39(10):1010428317734947. PMID: 28990465.

168. Sarrabayrouse G, Synaeve C, Leveque K, Favre G, Tilkin-Mariamé AF. Statins stimulate in vitro membrane FasL expression and lymphocyte apoptosis through RhoA/ROCK pathway in murine melanoma cells. Neoplasia. 2007;9(12):1078-90. PMID: 18084615.

169. Kaymak I, Maier CR, Schmitz W, Campbell AD, Dankworth B, Ade CP, Walz S, Paauwe M, Kalogirou C, Marouf H, et al. Mevalonate pathway provides ubiquinone to maintain pyrimidine synthesis and survival in p53-deficient cancer cells exposed to metabolic stress. Cancer Res. 2020;80(2):189-203. PMID: 31744820.

170. Jiao Z, Cai H, Long Y, Sirka OK, Padmanaban V, Ewald AJ, Devreotes PN. Statin-induced GGPP depletion blocks macropinocytosis and starves cells with oncogenic defects. Proc Natl Acad Sci U S A. 2020;117(8):4158-68. PMID: 32051246.

171. Yin L, He Z, Yi B, Xue L, Sun J. Simvastatin suppresses human breast cancer cell invasion by decreasing the expression of pituitary tumor-transforming gene 1. Front Pharmacol. 2020;11:574068. PMID: 33250768.

172. Freed-Pastor WA, Mizuno H, Zhao X, Langerød A, Moon SH, RodriguezBarrueco R, Barsotti A, Chicas A, Li W, Polotskaia A, et al. Mutant p53 disrupts mammary tissue architecture via the mevalonate pathway. Cell. 2012;148(1-2):244-58. PMID: 22265415.

173. Georgakopoulos-Soares I, Chartoumpekis DV, Kyriazopoulou V, Zaravinos A. EMT factors and metabolic pathways in cancer. Front Oncol. 2020;10:499. PMID: 32318352.

174. Koohestanimobarhan S, Salami S, Imeni V, Mohammadi Z, Bayat O. Lipophilic statins antagonistically alter the major epithelial-to-mesenchymal transition signaling pathways in breast cancer stem-like cells via inhibition of the mevalonate pathway. J Cell Biochem. 2018. https://doi. org/10.1002/jcb.27544. PMID: 30191610.
175. Göbel A, Zinna VM, Dell'Endice S, Jaschke N, Kuhlmann JD, Wimberger $P$, Rachner TD. Anti-tumor effects of mevalonate pathway inhibition in ovarian cancer. BMC Cancer. 2020;20(1):703. PMID: 32727400.

176. Zhong WB, Wang CY, Chang TC, Lee WS. Lovastatin induces apoptosis of anaplastic thyroid cancer cells via inhibition of protein geranylgeranylation and de novo protein synthesis. Endocrinology. 2003;144(9):3852-9. PMID: 12933658.

177. Kusama T, Mukai M, Iwasaki T, Tatsuta M, Matsumoto Y, Akedo H, Nakamura H. Inhibition of epidermal growth factor-induced RhoA translocation and invasion of human pancreatic cancer cells by 3-hydroxy-3-methylglutaryl-coenzyme a reductase inhibitors. Cancer Res. 2001;61(12):4885-91. PMID: 11406567.

178. Collisson EA, Kleer C, Wu M, De A, Gambhir SS, Merajver SD, Kolodney MS. Atorvastatin prevents RhoC isoprenylation, invasion, and metastasis in human melanoma cells. Mol Cancer Ther. 2003;2(10):941-8. PMID: 14578459.

179. White CP. On the occurrence of crystals in tumours. J Pathol Bacteriol. 1909:13(1):3-10.

180. Dessì S, Batetta B, Pulisci D, Spano O, Anchisi C, Tessitore L, Costelli P, Baccino FM, Aroasio E, Pani P. Cholesterol content in tumor tissues is inversely associated with high-density lipoprotein cholesterol in serum in patients with gastrointestinal cancer. Cancer. 1994;73(2):253-8. PMID: 8293385.

181. Kolanjiappan K, Ramachandran CR, Manoharan S. Biochemical changes in tumor tissues of oral cancer patients. Clin Biochem. 2003;36(1):61-5. PMID: 12554062.

182. Gueddari N, Favre G, Hachem H, Marek E, Le Gaillard F, Soula G. Evidence for up-regulated low density lipoprotein receptor in human lung adenocarcinoma cell line A549. Biochimie. 1993;75(9):811-9. PMID: 8274533.

183. Lum DF, McQuaid KR, Gilbertson VL, Hughes-Fulford M. Coordinate upregulation of low-density lipoprotein receptor and cyclo-oxygenase-2 gene expression in human colorectal cells and in colorectal adenocarcinoma biopsies. Int J Cancer. 1999;83(2):162-6. PMID: 10471521.

184. Yen CF, Kalunta CI, Chen FS, Kaptein JS, Lin CK, Lad PM. Regulation of low-density lipoprotein receptors and assessment of their functional role in Burkitt's lymphoma cells. Biochim Biophys Acta. 1995;1257(1):47-57. PMID: 7599180.

185. Tatidis L, Gruber A, Vitols S. Decreased feedback regulation of low density lipoprotein receptor activity by sterols in leukemic cells from patients with acute myelogenous leukemia. J Lipid Res. 1997:38(12):2436-45. PMID: 9458267.

186. Chen Y, Hughes-Fulford M. Human prostate cancer cells lack feedback regulation of low-density lipoprotein receptor and its regulator, SREBP2. Int J Cancer. 2001;91(1):41-5. PMID: 11149418.

187. Vitols S, Gahrton G, Ost A, Peterson C. Elevated low density lipoprotein receptor activity in leukemic cells with monocytic differentiation. Blood. 1984;63(5):1186-93. PMID: 6324928.

188. Rudling MJ, Ståhle L, Peterson CO, Skoog L. Content of low density lipoprotein receptors in breast cancer tissue related to survival of patients. Br Med J (Clin Res Ed). 1986;292(6520):580-2. PMID: 3081176.

189. Risbridger GP, Davis ID, Birrell SN, Tilley WD. Breast and prostate cancer: more similar than different. Nat Rev Cancer. 2010;10(3):205-12. PMID: 20147902.

190. Likus W, Siemianowicz K, Bieńk K, Pakuła M, Pathak H, Dutta C, Wang Q, Shojaei S, Assaraf YG, Ghavami S, et al. Could drugs inhibiting the mevalonate pathway also target cancer stem cells? Drug Resist Updat. 2016;25:13-25. PMID: 27155373.

191. Brown MS, Goldstein JL. The SREBP pathway: regulation of cholesterol metabolism by proteolysis of a membrane-bound transcription factor. Cell. 1997;89(3):331-40. PMID: 9150132.

192. Horton JD, Goldstein JL, Brown MS. SREBPs: activators of the complete program of cholesterol and fatty acid synthesis in the liver. J Clin Invest. 2002:109(9):1125-31. PMID: 11994399

193. Attie $A D$, Seidah NG. Dual regulation of the $L D L$ receptor-some clarity and new questions. Cell Metab. 2005;1(5):290-2. PMID: 16054075.

194. Brown MS, Goldstein JL. Cholesterol feedback: from Schoenheimer's bottle to Scap's MELADL. J Lipid Res. 2009;50 Suppl(Suppl):S15-27. PMID: 18974038.

195. Simons K, Ikonen E. How cells handle cholesterol. Science. 2000;290(5497):1721-6. PMID: 11099405. 
196. Moossavi M, Parsamanesh N, Bahrami A, Atkin SL, Sahebkar A. Role of the NLRP3 inflammasome in cancer. Mol Cancer. 2018;17(1):158. PMID 30447690.

197. Bae JY, Lee SW, Shin YH, Lee JH, Jahng JW, Park K. P2X7 receptor and NLRP3 inflammasome activation in head and neck cancer. Oncotarget. 2017:8(30):48972-82. PMID: 28430665.

198. Du Q, Wang Q, Fan H, Wang J, Liu X, Wang H, Wang Y, Hu R. Dietary cholesterol promotes AOM-induced colorectal cancer through activating the NLRP3 inflammasome. Biochem Pharmacol. 2016;105:42-54. PMID: 26921636.

199. Weichand B, Popp R, Dziumbla S, Mora J, Strack E, Elwakeel E, Frank AC, Scholich K, Pierre S, Syed SN, et al. S1PR1 on tumor-associated macrophages promotes lymphangiogenesis and metastasis via NLRP3/ IL-1ß. J Exp Med. 2017;214(9):2695-713. PMID: 28739604.

200. Mok EHK, Lee TKW. The pivotal role of the dysregulation of cholesterol homeostasis in cancer: implications for therapeutic targets. Cancers (Basel). 2020;12(6):1410. PMID: 32486083.

201. Chang TY, Li BL, Chang CC, Urano Y. Acyl-coenzyme A:cholesterol acyltransferases. Am J Physiol Endocrinol Metab. 2009;297(1):E1-9. PMID: 19141679.

202. Geng F, Cheng X, Wu X, Yoo JY, Cheng C, Guo JY, Mo X, Ru P, Hurwitz B, Kim SH, et al. Inhibition of SOAT1 suppresses glioblastoma growth via blocking SREBP-1-mediated lipogenesis. Clin Cancer Res. 2016;22(21):5337-48. PMID: 27281560

203. Jiang Y, Sun A, Zhao Y, Ying W, Sun H, Yang X, Xing B, Sun W, Ren L, Hu B, et al. Proteomics identifies new therapeutic targets of early-stage hepatocellular carcinoma. Nature. 2019:567(7747):257-61. PMID: 30814741.

204. Antalis CJ, Arnold T, Rasool T, Lee B, Buhman KK, Siddiqui RA. High ACAT1 expression in estrogen receptor negative basal-like breast cancer cells is associated with LDL-induced proliferation. Breast Cancer Res Treat. 2010;122(3):661-70. PMID: 19851860

205. Saraon P, Trudel D, Kron K, Dmitromanolakis A, Trachtenberg J, Bapat B, van der Kwast T, Jarvi KA, Diamandis EP. Evaluation and prognostic significance of ACAT1 as a marker of prostate cancer progression. Prostate. 2014;74(4):372-80. PMID: 24311408.

206. Goldstein JL, Brown MS. The LDL receptor. Arterioscler Thromb Vasc Biol. 2009;29(4):431-8. PMID: 19299327.

207. Tveten K, Strøm TB, Berge KE, Leren TP. PCSK9-mediated degradation of the $L D L$ receptor generates a $17 \mathrm{kDa} C$-terminal $L D L$ receptor fragment. J Lipid Res. 2013;54(6):1560-6. PMID: 23509406.

208. Athavale D, Chouhan S, Pandey V, Mayengbam SS, Singh S, Bhat MK. Hepatocellular carcinoma-associated hypercholesterolemia: involvement of proprotein-convertase-subtilisin-kexin type-9 (PCSK9). Cancer Metab. 2018;6:16. PMID: 30386595

209. Zhao C, Dahlman-Wright K. Liver X receptor in cholesterol metabolism. J Endocrinol. 2010;204(3):233-40. PMID: 19837721

210. Gelissen IC, Harris M, Rye KA, Quinn C, Brown AJ, Kockx M, Cartland S, Packianathan M, Kritharides $L$, Jessup W. ABCA1 and ABCG1 synergize to mediate cholesterol export to apoA-I. Arterioscler Thromb Vasc Biol. 2006;26(3):534-40. PMID: 16357317.

211. Daniil G, Zannis VI, Chroni A. Effect of apoA-I mutations in the capacity of reconstituted HDL to promote ABCG1-mediated cholesterol efflux. PLoS One. 2013;8(6):e67993. PMID: 23826352.

212. Lorenzi I, von Eckardstein A, Radosavljevic S, Rohrer L. Lipidation of apolipoprotein A-I by ATP-binding cassette transporter (ABC) A1 generates an interaction partner for $A B C G 1$ but not for scavenger receptor $\mathrm{BI}$. Biochim Biophys Acta. 2008;1781(6-7):306-13. PMID: 18485926.

213. Ouvrier A, Cadet R, Vernet P, Laillet B, Chardigny JM, Lobaccaro JM, Drevet JR, Saez F. LXR and ABCA1 control cholesterol homeostasis in the proximal mouse epididymis in a cell-specific manner. J Lipid Res. 2009;50(9):1766-75. PMID: 19395734

214. Bi DP, Yin CH, Zhang XY, Yang NN, Xu JY. MiR-183 functions as an oncogene by targeting ABCA1 in colon cancer. Oncol Rep. 2016;35(5):28739. PMID: 26935154.

215. Su C, Huang DP, Liu JW, Liu WY, Cao YO. miR-27a-3p regulates proliferation and apoptosis of colon cancer cells by potentially targeting BTG1. Oncol Lett. 2019;18(3):2825-34. PMID: 31452761.

216. Wang Q, Feng F, Wang J, Ren M, Shi Z, Mao X, Zhang H, Ju X. Liver $X$ receptor activation reduces gastric cancer cell proliferation by suppressing Wnt signalling via LXRß relocalization. J Cell Mol Med. 2019;23(2):789-97. PMID: 30338932.
217. Huang P, Nedelcu D, Watanabe M, Jao C, Kim Y, Liu J, Salic A. Cellular cholesterol directly activates smoothened in hedgehog signaling. Cell. 2016;166(5):1176-1187.e1114. PMID: 27545348.

218. Carpenter RL, Lo HW. Hedgehog pathway and GLI1 isoforms in human cancer. Discov Med. 2012;13(69):105-13. PMID: 22369969.

219. Gordon RE, Zhang L, Peri S, Kuo YM, Du F, Egleston BL, Ng JMY, Andrews AJ, Astsaturov I, Curran T, et al. Statins synergize with hedgehog pathway inhibitors for treatment of medulloblastoma. Clin Cancer Res. 2018;24(6):1375-88. PMID: 29437795.

220. Fan Q, Gong T, Zheng C, Ng JMY, Chen J, Myers C, Hensley H, Curran T, Yang ZJ. Statins repress hedgehog signaling in medulloblastoma with no bone toxicities. Oncogene. 2021;40(12):2258-72. PMID: 33649536.

221. Ghaderi A, Vahdati-Mashhadian N, Oghabian Z, Moradi V, Afshari $\mathrm{R}$, Mehrpour O. Thallium exists in opioid poisoned patients. Daru. 2015;23(1):39. PMID: 26231176.

222. Samarghandian S, Ohata H, Yamauchi N, Shibasaki T. Corticotropinreleasing factor as well as opioid and dopamine are involved in tailpinch-induced food intake of rats. Neuroscience. 2003;116(2):519-24. PMID: 12559107.

223. Samarghandian S, Azimi-Nezhad M, Farkhondeh T, Samini F. Antioxidative effects of curcumin on immobilization-induced oxidative stress in rat brain, liver and kidney. Biomed Pharmacother. 2017;87:223-9. PMID: 28061405.

224. Udristioiu A, Nica-Badea D. Autophagy dysfunctions associated with cancer cells and their therapeutic implications. Biomed Pharmacother. 2019;115:108892. PMID: 31029889.

225. Galluzzi L, Green DR. Autophagy-independent functions of the autophagy machinery. Cell. 2019;177(7):1682-99. PMID: 31199916.

226. Rybstein MD, Bravo-San Pedro JM, Kroemer G, Galluzzi L. The autophagic network and cancer. Nat Cell Biol. 2018;20(3):243-51. PMID: 29476153.

227. van Beek N, Klionsky DJ, Reggiori F. Genetic aberrations in macroautophagy genes leading to diseases. Biochim Biophys Acta Mol Cell Res. 2018;1865(5):803-16. PMID: 29524522.

228. White E. Deconvoluting the context-dependent role for autophagy in cancer. Nat Rev Cancer. 2012;12(6):401-10. PMID: 22534666.

229. Jin S. Autophagy, mitochondrial quality control, and oncogenesis. Autophagy. 2006;2(2):80-4. PMID: 16874075.

230. Narita M, Young AR, Narita M. Autophagy facilitates oncogeneinduced senescence. Autophagy. 2009;5(7):1046-7. PMID: 19652542.

231. Ma Y, Galluzzi L, Zitvogel L, Kroemer G. Autophagy and cellular immune responses. Immunity. 2013;39(2):211-27. PMID: 23973220.

232. Kenific CM, Debnath J. Cellular and metabolic functions for autophagy in cancer cells. Trends Cell Biol. 2015;25(1):37-45. PMID: 25278333.

233. Degenhardt K, Mathew R, Beaudoin B, Bray K, Anderson D, Chen G, Mukherjee C, Shi Y, Gélinas C, Fan Y, et al. Autophagy promotes tumor cell survival and restricts necrosis, inflammation, and tumorigenesis. Cancer Cell. 2006;10(1):51-64. PMID: 16843265.

234. Yadav RK, Chae SW, Kim HR, Chae HJ. Endoplasmic reticulum stress and cancer. J Cancer Prev. 2014;19(2):75-88. PMID: 25337575.

235. Araki M, Motojima K. Hydrophobic statins induce autophagy in cultured human rhabdomyosarcoma cells. Biochem Biophys Res Commun. 2008;367(2):462-7. PMID: 18178158.

236. Araki M, Maeda M, Motojima K. Hydrophobic statins induce autophagy and cell death in human rhabdomyosarcoma cells by depleting geranylgeranyl diphosphate. Eur J Pharmacol. 2012;674(23):95-103. PMID: 22094060.

237. Yang Z, Su Z, DeWitt JP, Xie L, Chen Y, Li X, Han L, Li D, Xia J, Zhang Y, et al. Fluvastatin prevents lung adenocarcinoma bone metastasis by triggering autophagy. EBioMedicine. 2017;19:49-59. PMID: 28454732.

238. Misirkic M, Janjetovic K, Vucicevic L, Tovilovic G, Ristic B, Vilimanovich U, Harhaji-Trajkovic L, Sumarac-Dumanovic M, Micic D, Bumbasirevic $V$, et al. Inhibition of AMPK-dependent autophagy enhances in vitro antiglioma effect of simvastatin. Pharmacol Res. 2012;65(1):111-9. PMID: 21871960.

239. Vilimanovich $U$, Bosnjak M, Bogdanovic A, Markovic I, Isakovic A, Kravic-Stevovic T, Mircic A, Trajkovic V, Bumbasirevic V. Statinmediated inhibition of cholesterol synthesis induces cytoprotective autophagy in human leukemic cells. Eur J Pharmacol. 2015;765:41528. PMID: 26358205. 
240. Yang PM, Liu YL, Lin YC, Shun CT, Wu MS, Chen CC. Inhibition of autophagy enhances anticancer effects of atorvastatin in digestive malignancies. Cancer Res. 2010;70(19):7699-709. PMID: 20876807.

241. Asakura K, Izumi Y, Yamamoto M, Yamauchi Y, Kawai K, Serizawa A, Mizushima T, Ohmura M, Kawamura M, Wakui M, et al. The cytostatic effects of lovastatin on ACC-MESO-1 cells. J Surg Res. 2011;170(2):e197-209. PMID: 21816418.

242. Wojtkowiak JW, Sane KM, Kleinman M, Sloane BF, Reiners JJ Jr, Mattingly RR. Aborted autophagy and nonapoptotic death induced by farnesyl transferase inhibitor and lovastatin. J Pharmacol Exp Ther. 2011;337(1):65-74. PMID: 21228063.

243. Hu MB, Zhang JW, Gao JB, Qi YW, Gao Y, Xu L, Ma Y, Wei ZZ. Atorvastatin induces autophagy in MDA-MB-231 breast cancer cells. Ultrastruct Pathol. 2018;42(5):409-15. PMID: 30300062.

244. Shi Y, Felley-Bosco E, Marti TM, Stahel RA. Differential effects of lovastatin on cisplatin responses in normal human mesothelial cells versus cancer cells: implication for therapy. PLoS One. 2012;7(9):e45354. PMID: 23028957.

245. Hombach-Klonisch S, Mehrpour M, Shojaei S, Harlos C, Pitz M, Hamai A, Siemianowicz K, Likus W, Wiechec E, Toyota BD, et al. Glioblastoma and chemoresistance to alkylating agents: involvement of apoptosis, autophagy, and unfolded protein response. Pharmacol Ther. 2018;184:1341. PMID: 29080702.

246. Yan Y, Xu Z, Dai S, Qian L, Sun L, Gong Z. Targeting autophagy to sensitive glioma to temozolomide treatment. J Exp Clin Cancer Res. 2016;35:23. PMID: 26830677.

247. Sheng B, Song Y, Zhang J, Li R, Wang Z, Zhu X. Atorvastatin suppresses the progression of cervical cancer via regulation of autophagy. Am J Transl Res. 2020;12(9):5252-68. PMID: 33042417.

248. Dixon SJ, Lemberg KM, Lamprecht MR, Skouta R, Zaitsev EM, Gleason CE, Patel DN, Bauer AJ, Cantley AM, Yang WS, et al. Ferroptosis: an irondependent form of nonapoptotic cell death. Cell. 2012;149(5):1060-72. PMID: 22632970.

249. Galluzzi L, Vitale I, Aaronson SA, Abrams JM, Adam D, Agostinis P, Alnemri ES, Altucci L, Amelio I, Andrews DW, et al. Molecular mechanisms of cell death: recommendations of the Nomenclature Committee on Cell Death 2018. Cell Death Differ. 2018;25(3):486-541. PMID: 29362479.

250. Tang D, Kang R, Berghe TV, Vandenabeele P, Kroemer G. The molecular machinery of regulated cell death. Cell Res. 2019;29(5):347-64. PMID: 30948788.

251. Xie Y, Hou W, Song X, Yu Y, Huang J, Sun X, Kang R, Tang D. Ferroptosis: process and function. Cell Death Differ. 2016;23(3):369-79. PMID: 26794443.

252. Qiu Y, Cao Y, Cao W, Jia Y, Lu N. The application of ferroptosis in diseases. Pharmacol Res. 2020;159:104919. PMID: 32464324.

253. Jiang L, Kon N, Li T, Wang SJ, Su T, Hibshoosh H, Baer R, Gu W. Ferroptosis as a p53-mediated activity during tumour suppression. Nature. 2015;520(7545):57-62. PMID: 25799988.

254. Zhang Y, Shi J, Liu X, Feng L, Gong Z, Koppula P, Sirohi K, Li X, Wei Y, Lee $\mathrm{H}$, et al. BAP1 links metabolic regulation of ferroptosis to tumour suppression. Nat Cell Biol. 2018;20(10):1181-92. PMID: 30202049.

255. Ubellacker JM, Tasdogan A, Ramesh V, Shen B, Mitchell EC, MartinSandoval MS, Gu Z, McCormick ML, Durham AB, Spitz DR, et al. Lymph protects metastasizing melanoma cells from ferroptosis. Nature. 2020;585(7823):113-8. PMID: 32814895.

256. Hong X, Roh W, Sullivan RJ, Wong KHK, Wittner BS, Guo H, Dubash TD, Sade-Feldman M, Wesley B, Horwitz E, et al. The lipogenic regulator SREBP2 induces transferrin in circulating melanoma cells and suppresses ferroptosis. Cancer Discov. 2021;11(3):678-95. PMID: 33203734.

257. Belavgeni A, Bornstein SR, von Mässenhausen A, Tonnus W, Stumpf J, Meyer C, Othmar E, Latk M, Kanczkowski W, Kroiss M, et al. Exquisite sensitivity of adrenocortical carcinomas to induction of ferroptosis. Proc Natl Acad Sci U S A. 2019;1 16(44):22269-74. PMID: 31611400.

258. Basuli D, Tesfay L, Deng Z, Paul B, Yamamoto Y, Ning G, Xian W, McKeon F, Lynch M, Crum CP, et al. Iron addiction: a novel therapeutic target in ovarian cancer. Oncogene. 2017;36(29):4089-99. PMID: 28319068.

259. Bersuker K, Hendricks JM, Li Z, Magtanong L, Ford B, Tang PH, Roberts MA, Tong B, Maimone TJ, Zoncu R, et al. The CoQ oxidoreductase FSP1 acts parallel to GPX4 to inhibit ferroptosis. Nature. 2019;575(7784):68892. PMID: 31634900 .
260. Doll S, Freitas FP, Shah R, Aldrovandi M, da Silva MC, Ingold I, Goya Grocin A, Xavier da Silva TN, Panzilius E, Scheel CH, et al. FSP1 is a glutathione-independent ferroptosis suppressor. Nature. 2019;575(7784):693-8. PMID: 31634899.

261. Kraft VAN, Bezjian CT, Pfeiffer S, Ringelstetter L, Müller C, Zandkarimi F, Merl-Pham J, Bao X, Anastasov N, Kössl J, et al. GTP cyclohydrolase 1/ tetrahydrobiopterin counteract ferroptosis through lipid remodeling. ACS Cent Sci. 2020;6(1):41-53. PMID: 31989025.

262. Moosmann B, Behl C. Selenoproteins, cholesterol-lowering drugs, and the consequences: revisiting of the mevalonate pathway. Trends Cardiovasc Med. 2004;14(7):273-81. PMID: 15542379.

263. Friedmann Angeli JP, Conrad M. Selenium and GPX4, a vital symbiosis. Free Radic Biol Med. 2018;127:153-9. PMID: 29522794.

264. Viswanathan VS, Ryan MJ, Dhruv HD, Gill S, Eichhoff OM, Seashore-Ludlow B, Kaffenberger SD, Eaton JK, Shimada K, Aguirre AJ, et al. Dependency of a therapy-resistant state of cancer cells on a lipid peroxidase pathway. Nature. 2017;547(7664):453-7. PMID: 28678785.

265. Shimada K, Hayano M, Pagano NC, Stockwell BR. Cell-Line selectivity improves the predictive power of pharmacogenomic analyses and helps identify NADPH as biomarker for ferroptosis sensitivity. Cell Chem Biol. 2016;23(2):225-35. PMID: 26853626.

266. Wallach D, Kang TB, Dillon CP, Green DR. Programmed necrosis in inflammation: toward identification of the effector molecules. Science. 2016;352(6281):aaf2154. PMID: 27034377.

267. Shi J, Gao W, Shao F. Pyroptosis: gasdermin-mediated programmed necrotic cell death. Trends Biochem Sci. 2017;42(4):245-54. PMID: 27932073.

268. Zychlinsky A, PrevostMC, Sansonetti PJ. Shigella flexneri induces apoptosis in infected macrophages. Nature. 1992;358(6382):167-9. PMID: 1614548.

269. Zaki MH, Lamkanfi M, Kanneganti TD. The Nlrp3 inflammasome: contributions to intestinal homeostasis. Trends Immunol. 2011;32(4):171-9. PMID: 21388882.

270. Wallach D, Kang TB, Kovalenko A. Concepts of tissue injury and cell death in inflammation: a historical perspective. Nat Rev Immunol. 2014;14(1):51-9. PMID: 24336099.

271. Shi J, Zhao Y, Wang K, Shi X, Wang Y, Huang H, Zhuang Y, Cai T, Wang F, Shao F. Cleavage of GSDMD by inflammatory caspases determines pyroptotic cell death. Nature. 2015;526(7575):660-5. PMID: 26375003.

272. Ding J, Wang K, Liu W, She Y, Sun Q, Shi J, Sun H, Wang DC, Shao F. Poreforming activity and structural autoinhibition of the gasdermin family. Nature. 2016;535(7610):111-6. PMID: 27281216.

273. He WT, Wan H, Hu L, Chen P, Wang X, Huang Z, Yang ZH, Zhong $C Q$, Han J. Gasdermin D is an executor of pyroptosis and required for interleukin-1 $\beta$ secretion. Cell Res. 2015;25(12):1285-98. PMID: 26611636.

274. Kayagaki N, Stowe IB, Lee BL, O'Rourke K, Anderson K, Warming S, Cuellar T, Haley B, Roose-Girma M, Phung QT, et al. Caspase-11 cleaves gasdermin D for non-canonical inflammasome signalling. Nature. 2015;526(7575):666-71. PMID: 26375259.

275. Rogers C, Fernandes-Alnemri T, Mayes L, Alnemri D, Cingolani G, Alnemri ES. Cleavage of DFNA5 by caspase-3 during apoptosis mediates progression to secondary necrotic/pyroptotic cell death. Nat Commun. 2017:8:14128. PMID: 28045099.

276. Wang Y, Gao W, Shi X, Ding J, Liu W, He H, Wang K, Shao F. Chemotherapy drugs induce pyroptosis through caspase-3 cleavage of a gasdermin. Nature. 2017;547(7661):99-103. PMID: 28459430.

277. Aachoui Y, Sagulenko V, Miao EA, Stacey KJ. Inflammasome-mediated pyroptotic and apoptotic cell death, and defense against infection. Curr Opin Microbiol. 2013;16(3):319-26. PMID: 23707339.

278. Kovacs SB, Miao EA. Gasdermins: effectors of pyroptosis. Trends Cell Biol. 2017;27(9):673-84. PMID: 28619472.

279. Aglietti RA, Dueber EC. Recent insights into the molecular mechanisms underlying pyroptosis and gasdermin family functions. Trends Immunol. 2017;38(4):261-71. PMID: 28196749.

280. Wang WJ, Chen D, Jiang MZ, Xu B, Li XW, Chu Y, Zhang YJ, Mao R, Liang J, Fan DM. Downregulation of gasdermin D promotes gastric cancer proliferation by regulating cell cycle-related proteins. J Dig Dis. 2018;19(2):74-83. PMID: 29314754.

281. Zhou B, Zhang JY, Liu XS, Chen HZ, Ai YL, Cheng K, Sun RY, Zhou D, Han J, Wu Q. Tom20 senses iron-activated ROS signaling to promote melanoma cell pyroptosis. Cell Res. 2018;28(12):1171-85. PMID: 30287942. 
282. Wu LM, Wu SG, Chen F, Wu Q, Wu CM, Kang CM, He X, Zhang RY, Lu ZF, $\mathrm{Li} \mathrm{XH}$, et al. Atorvastatin inhibits pyroptosis through the IncRNA NEXNAS1/NEXN pathway in human vascular endothelial cells. Atherosclerosis. 2020;293:26-34. PMID: 31830726.

283. Chen A, Chen Z, Zhou Y, Wu Y, Xia Y, Lu D, Fan M, Li S, Chen J, Sun A, et al. Rosuvastatin protects against coronary microembolizationinduced cardiac injury via inhibiting NLRP3 inflammasome activation. Cell Death Dis. 2021;12(1):78. PMID: 33436548.

284. Merlo LM, Pepper JW, Reid BJ, Maley CC. Cancer as an evolutionary and ecological process. Nat Rev Cancer. 2006;6(12):924-35. PMID: 17109012.

285. Jin MZ, Jin WL. The updated landscape of tumor microenvironment and drug repurposing. Signal Transduct Target Ther. 2020;5(1):166. PMID: 32843638.

286. Jin H, He Y, Zhao P, Hu Y, Tao J, Chen J, Huang Y. Targeting lipid metabolism to overcome EMT-associated drug resistance via integrin $\beta 3 / F A K$ pathway and tumor-associated macrophage repolarization using legumain-activatable delivery. Theranostics. 2019;9(1):265-78. PMID: 30662566.

287. Wolfe AR, Trenton NJ, Debeb BG, Larson R, Ruffell B, Chu K, Hittelman W, Diehl $M$, Reuben JM, Ueno NT, et al. Mesenchymal stem cells and macrophages interact through IL-6 to promote inflammatory breast cancer in preclinical models. Oncotarget. 2016;7(50):82482-92. PMID: 27756885.

288. Qiu GZ, Jin MZ, Dai JX, Sun W, Feng JH, Jin WL. Reprogramming of the tumor in the hypoxic niche: the emerging concept and associated therapeutic strategies. Trends Pharmacol Sci. 2017;38(8):669-86. PMID: 28602395.

289. Palazon A, Tyrakis PA, Macias D, Veliça P, Rundqvist H, Fitzpatrick S, Vojnovic N, Phan AT, Loman N, Hedenfalk I, et al. An HIF-1a/NEGF-A axis in cytotoxic T cells regulates tumor progression. Cancer Cell. 2017;32(5):669-683.e665. PMID: 29136509

290. Ribatti D. Tumor refractoriness to anti-VEGF therapy. Oncotarget. 2016;7(29):46668-77. PMID: 27081695.

291. Fukumura D, Xu L, Chen Y, Gohongi T, Seed B, Jain RK. Hypoxia and acidosis independently up-regulate vascular endothelial growth factor transcription in brain tumors in vivo. Cancer Res. 2001;61(16):6020-4. PMID: 11507045.

292. Fukamachi T, Wang X, Mochizuki Y, Maruyama C, Saito H, Kobayashi H. Acidic environments enhance the inhibitory effect of statins on proliferation of synovial cells. Int Immunopharmacol. 2013;17(1):148-53. PMID: 23769886.

293. McFarland AJ, Anoopkumar-Dukie S, Arora DS, Grant GD, McDermott CM, Perkins AV, Davey AK. Molecular mechanisms underlying the effects of statins in the central nervous system. Int J Mol Sci. 2014;15(11):20607-37. PMID: 25391045.

294. Otruba P, Kanovsky P, Hlustik P. Treatment with statins and involvement of the peripheral nervous system: results of a prospective clinical and neurophysiological follow-up. Biomed Pap Med Fac Univ Palacky Olomouc Czech Repub. 2007;151(2):307-10. PMID: 18345269.

295. Svendsen TK, Krøigård T, Wirenfeldt M, Schrøder HD, Bak S, Möller S, Hallas J, Sindrup SH, Gaist D. Statin use and peripheral nerve function-a prospective follow-up study. Basic Clin Pharmacol Toxicol. 2020;126(3):203-11. PMID: 31505101.

296. Longo J, van Leeuwen JE, Elbaz M, Branchard E, Penn LZ. Statins as anticancer agents in the era of precision medicine. Clin Cancer Res. 2020;26(22):5791-800. PMID: 32887721.

297. McGregor GH, Campbell AD, Fey SK, Tumanov S, Sumpton D, Blanco GR, Mackay G, Nixon C, Vazquez A, Sansom OJ, et al. Targeting the metabolic response to statin-mediated oxidative stress produces a synergistic antitumor response. Cancer Res. 2020;80(2):175-88. PMID: 31562248

298. Taccioli C, Sorrentino G, Zannini A, Caroli J, Beneventano D, Anderlucci L, Lolli M, Bicciato S, Del Sal G. MDP, a database linking drug response data to genomic information, identifies dasatinib and statins as a combinatorial strategy to inhibit YAP/TAZ in cancer cells. Oncotarget. 2015;6(36):38854-65. PMID: 26513174.

299. lannelli F, Roca MS, Lombardi R, Ciardiello C, Grumetti L, De Rienzo S, Moccia T, Vitagliano C, Sorice A, Costantini S, et al. Synergistic antitumor interaction of valproic acid and simvastatin sensitizes prostate cancer to docetaxel by targeting CSCs compartment via YAP inhibition. J Exp Clin Cancer Res. 2020;39(1):213. PMID: 33032653.

300. Li Y, Xian M, Yang B, Ying M, He Q. Inhibition of KLF4 by statins reverses adriamycin-induced metastasis and cancer stemness in osteosarcoma cells. Stem Cell Rep. 2017;8(6):1617-29. PMID: 28552603.
301. Luput L, Sesarman A, Porfire A, Achim M, Muntean D, Casian T, Patras L, Rauca VF, Drotar DM, Stejerean I, et al. Liposomal simvastatin sensitizes C26 murine colon carcinoma to the antitumor effects of liposomal 5-fluorouracil in vivo. Cancer Sci. 2020;111(4):1344-56. PMID: 31960547.

302. Pereira PMR, Mandleywala K, Ragupathi A, Lewis JS. Acute statin treatment improves antibody accumulation in EGFR- and PSMA-expressing tumors. Clin Cancer Res. 2020;26(23):6215-29. PMID: 32998959.

303. Zhang Y, Liu Y, Duan J, Wang H, Zhang Y, Qiao K, Wang J. Cholesterol depletion sensitizes gallbladder cancer to cisplatin by impairing DNA damage response. Cell Cycle. 2019;18(23):3337-50. PMID: 31599189.

304. Nguyen PA, Chang CC, Galvin CJ, Wang YC, An SY, Huang CW, Wang YH, Hsu MH, Li YJ, Yang HC. Statins use and its impact in EGFR-TKIs resistance to prolong the survival of lung cancer patients: a cancer registry cohort study in Taiwan. Cancer Sci. 2020;111(8):2965-73. PMID: 32441434.

305. Cortellini A, Tucci M, Adamo V, Stucci LS, Russo A, Tanda ET, Spagnolo F, Rastelli F, Bisonni R, Santini D, et al. Integrated analysis of concomitant medications and oncological outcomes from PD-1/PD-L1 checkpoint inhibitors in clinical practice. J Immunother Cancer. 2020;8(2):e001361. PMID: 33154150

306. Jiménez-Vacas JM, Herrero-Aguayo V, Montero-Hidalgo AJ, Sáez-Martínez P, Gómez-Gómez E, León-González AJ, Fuentes-Fayos AC, YuberoSerrano EM, Requena-Tapia MJ, López M, et al. Clinical, cellular, and molecular evidence of the additive antitumor effects of biguanides and statins in prostate cancer. J Clin Endocrinol Metab. 2021;106(2):e696710. PMID: 33247590.

307. Longo J, Pandyra AA, Stachura P, Minden MD, Schimmer AD, Penn LZ. Cyclic AMP-hydrolyzing phosphodiesterase inhibitors potentiate statininduced cancer cell death. Mol Oncol. 2020;14(10):2533-45. PMID: 32749766.

308. Bertolini P, Lassalle M, Mercier G, Raquin MA, Izzi G, Corradini N, Hartmann O. Platinum compound-related ototoxicity in children: long-term follow-up reveals continuous worsening of hearing loss. J Pediatr Hematol Oncol. 2004;26(10):649-55. PMID: 15454836.

309. Coradini PP, Cigana L, Selistre SG, Rosito LS, Brunetto AL. Ototoxicity from cisplatin therapy in childhood cancer. J Pediatr Hematol Oncol. 2007;29(6):355-60. PMID: 17551394.

310. Frisina RD, Wheeler HE, Fossa SD, Kerns SL, Fung C, Sesso HD, Monahan PO, Feldman DR, Hamilton R, Vaughn DJ, et al. Comprehensive audiometric analysis of hearing impairment and tinnitus after cisplatinbased chemotherapy in survivors of adult-onset cancer. J Clin Oncol. 2016;34(23):2712-20. PMID: 27354478.

311. Knight KR, Chen L, Freyer D, Aplenc R, Bancroft M, Bliss B, Dang H, Gillmeister B, Hendershot E, Kraemer DF, et al. Group-wide, prospective study of ototoxicity assessment in children receiving cisplatin chemotherapy (ACCL05C1): a report from the Children's Oncology Group. J Clin Oncol. 2017;35(4):440-5. PMID: 27937095

312. Marnitz S, Schermeyer L, Dommerich S, Köhler C, Olze H, Budach V, Martus P. Age-corrected hearing loss after chemoradiation in cervical cancer patients. Strahlenther Onkol. 2018;194(11):1039-48. PMID: 30120496.

313. Fernandez KA, Allen P, Campbell M, Page B, Townes T, Li CM, Cheng $\mathrm{H}$, Garrett J, Mulquin M, Clements A, et al. Atorvastatin is associated with reduced cisplatin-induced hearing loss. J Clin Invest. 2021;131(1):e142616. PMID: 33393488.

314. Abdel-Qadir H, Bobrowski D, Zhou L, Austin PC, Calvillo-Argüelles O, Amir E, Lee DS, Thavendiranathan P. Statin exposure and risk of heart failure after anthracycline- or trastuzumab-based chemotherapy for early breast cancer: a propensity score-matched cohort study. J Am Heart Assoc. 2021;10(2):e018393. PMID: 33401953.

315. Pan T, Lin SC, Lee YC, Yu G, Song JH, Pan J, Titus M, Satcher RL, Panaretakis $T$, Logothetis $C$, et al. Statins reduce castration-induced bone marrow adiposity and prostate cancer progression in bone. Oncogene. 2021;40(27):4592-603. PMID: 34127814.

\section{Publisher's Note}

Springer Nature remains neutral with regard to jurisdictional claims in published maps and institutional affiliations. 